\title{
АУОденита
}

В.Т. Ивашкин ${ }^{1}$, И.В. Маев², Т.Л. Лапина ${ }^{1, *}$, Е.Д. Федоров ${ }^{3}$, А.А. Шептулин ${ }^{1}$, А.С. Трухманов ${ }^{1}$, А.В. Кононов ${ }^{4}$, Р.А. Абдулхаков ${ }^{5}$, О.П. Алексеева ${ }^{6}$, С.А. Алексеенко Д.Н. Андреев ${ }^{2}$ Е.К. Баранская ${ }^{1}$, Н.И. Дехнич ${ }^{8}$, И.Л. Кляритская ${ }^{9}$, Р.С. Козлов ${ }^{8}$ Е.А. Коган ${ }^{1}$, М.П. Королев ${ }^{10}$, Н.В. Корочанская ${ }^{11}$, С.А. Курилович ${ }^{12}$, М.А. Ливзан ${ }^{4}$ М.Ф. Осипенко ${ }^{12}$, П.В. Павлов ${ }^{1}$, С.С. Пирогов ${ }^{13}$, А.С. Сарсенбаева ${ }^{14}$, В.И. Симаненков ${ }^{15}$, А.С.Тертычный ${ }^{1}$, А.В. Ткачев ${ }^{16}$, Ю.П. Успенский ${ }^{10}$, И.Б. Хлынов ${ }^{17}$, В.В. Цуканов ${ }^{18}$

${ }^{1}$ ФГАОУ ВО «Первый Московский государственный медицинский университет им. И.М. Сеченова» (Сеченовский Университет) Министерства здравоохранения Российской Федерации, Москва, Российская Федерация

${ }^{2}$ ФГБУ ВО «Московский государственный медико-стоматологический университет им. А.И. Евдокимова»

Министерства здравоохранения Российской Федерации, Москва, Российская Федерация

${ }^{3}$ ФГАОУ ВО «Российский нащиональный исследовательский медицинский университет им. Н.И. Пирогова»

Министерства здравоохранения Российской Федерачии, Москва, Российская Федерачия

${ }^{4}$ ФГБОУ ВО «Омский государственный медищинский университет» Министерства здравоохранения

Российской Федерачии, Омск, Российская Федерачия

${ }_{5}^{5}$ ФГБОУ ВО «Казанский государственный медицинский университет» Министерства здравоохранения

Российской Федерачии, Казань, Российская Федерачия

${ }^{6}$ ФГБОУ ВО «Приволжский исследовательский медицинский университет» Министерства здравоохранения

Российской Федерации, Нижний Новгород, Российская Федерачия

${ }^{7}$ ФГБОУ ВО «Дальневосточный государственный медицинский университет» Министерства здравоохранения

Российской Федерации, Хабаровск, Российская Федерация

${ }^{8}$ ФГБОУ ВО «Смоленский государственный медицинский университет» Министерства здравоохранения

Российской Федерачии, Смоленск, Российская Федерация

${ }_{9}^{9}$ ФГОУ ВО «Крымский федеральный университет им. В.И. Вернадского» Министерства образования и науки

Российской Федеращии, Симферополь, Российская Федерация

${ }^{10}$ ФГБОУ ВО «Санкт-Петербургский государственный педиатрический медицинский университет»

Министерства здравоохранения Российской Федерации, Санкт-Петербург, Российская Федерачия

11 ФГБОУ ВО «Кубанский государственный медицинкий университет» Министерства здравоохранения

Российской Федерачии, Краснодар, Российская Федеращия

${ }_{12}^{12}$ Научно-исследовательский институт терапии и профилактической медицинь -

филиал ФГБНУ «Федеральный исследовательский центр Институт цитологии и генетики Сибирского отделения

Российской академии наук», Новосибирск, Российская Федерация

${ }^{13}$ Московский научно-исследовательский онкологический институт им. П.А. Герцена -

филиал ФГБУ «Начиональный медищнский исследовательский центр радиологии»

Министерства здравоохранения Российской Федеращии, Москва, Российская Федерачия

${ }_{14}$ ФГБОУ ВО «Южно-Уральский государственный медицинский университет» Министерства здравоохранения

Российской Федерации, Челябинск, Российская Федерация

${ }^{15}$ ФБГОУ ВО «Северо-Западный государственный медицинский университет им. И.И. Мечникова»

Министерства здравоохранения Российской Федераци, Санкт-Петербург, Российская Федерачия

${ }^{16}$ ФГБОУ ВО «Ростовский государственный медицинский университет» Министерства здравоохранения

Российской Федерации, Ростов-на-Дону, Российская Федеращия

17 ФГБОУ ВО «Уральский государственный медиџинский университет» Министерства здравоохранения Российской Федерачии, Екатеринбург, Российская Федерация

${ }_{18}^{18}$ ФГНУ «Федеральный исследовательский центр “Красноярский научный центр Сибирского отделения

Российской академии наук”», обособленное подразделение НИИ медищинских проблем Севера, Красноярск,

Российская Федерачия 
Цель представления клинических рекомендаций заключается в обеспечении информационной поддержки принятия врачами решений, способствующих повышению качества оказания медицинской помощи пациенту с гастритом и дуоденитом с учетом новейших клинических данных и принципов доказательной медицины. Основное содержание. Гастрит - воспалительное заболевание слизистой оболочки желудка. Различают острый и хронический гастриты. Хронический гастрит - группа хронических заболеваний, которые морфологически характеризуются персистирующим воспалительным инфильтратом и нарушением клеточного обновления с развитием кишечной метаплазии, атрофии и эпителиальной дисплазии в слизистой оболочке желудка. С целью подтверждения диагноза гастрита и дуоденита, диагностики предраковых состояний и/или изменений слизистой оболочки желудка рекомендуется проведение эзофагогастродуоденоскопии (ЭГдС), при возможности ЭГДС высокого разрешения и виртуальной хромоэндоскопии с увеличением или без него, в том числе для выполнения прицельной биопсии с целью оценки стадии атрофии и кишечной метаплазии и выявления неоплазии. Всем пациентам с хроническим гастритом с положительными результатами тестирования на $H$. pylori в качестве этиологического лечения, а также с целью профилактики рака желудка рекомендуется проведение эрадикационной терапии. Пациентам с хроническим гастритом и симптомами диспепсии (боль и жжение в эпигастрии, переполнение в эпигастрии, чувство раннего насыщения), в том числе в сочетании с функциональной диспепсией, в качестве симптоматического лечения могут быть рекомендованы ингибиторы протонной помпы, прокинетики, ребамипид, висмута трикалия дицитрат. Пациентам с кишечной метаплазией, ограниченной одной анатомической областью, в большинстве случаев не рекомендуется наблюдение, особенно если высококачественное эндоскопическое исследование с биопсией позволило исключить выраженные стадии атрофического гастрита. Однако при наличии у таких пациентов отягощенного по раку желудка семейного анамнеза, неполной кишечной метаплазии, персистенции инфекции H. pylori им рекомендуется эндоскопическое наблюдение с хромоэндоскопией и прицельной биопсией 1 раз в 3 года. Пациентам с выраженным атрофическим гастритом рекомендуется высококачественное эндоскопическое наблюдение каждые 3 года. Пациентам с выраженным атрофическим гастритом с отягощенным наследственным анамнезом по раку желудка рекомендуется эндоскопическое наблюдение 1 раз в 1-2 года. Заключение. В клинических рекомендациях представлены актуальные данные об этиологии и патогенезе гастрита и дуоденита, методах лабораторной и инструментальной диагностики, основных подходах к этиологической эрадикационной терапии Н. pylori и лечению симптомов диспепсии.

Ключевые слова: гастрит, дуоденит, Helicobacter pylori, диспепсия, атрофия, метаплазия, дисплазия Конфликт интересов: авторы заявляют об отсутствии конфликта интересов.

Для цитирования: Ивашкин В.Т., Маев И.В., Лапина Т.Л., Федоров Е.Д., Шептулин А.А., Трухманов А.С., Кононов А.В., Абдулхаков Р.А., Алексеева О.П., Алексеенко С.А., Андреев Д.Н., Баранская Е.К., Дехнич Н.И., Кляритская И.Л., Козлов Р.С., Коган Е.А., Королев М.П., Корочанская Н.В., Курилович С.А., Ливзан М.А., Осипенко М.Ф., Павлов П.В., Пирогов С.С., Сарсенбаева А.С., Симаненков В.И., Тертычный А.С., Ткачев А.В., Успенский Ю.П., Хлынов И.Б., Цуканов В.В. Клинические рекомендации Российской гастроэнтерологической ассоциации и ассоциации «Эндоскопическое общество РЭнДО» по диагностике и лечению гастрита, дуоденита. Российский журнал гастроэнтерологии, гепатологии, колопроктологии. 2021;31(4):70-99. https://doi.org/10.22416/1382-4376-2021-31-4-70-99

\section{Clinical Recommendations of Russian Gastroenterological Association and RENDO Endoscopic Society on Diagnosis and Treatment of Gastritis and Duodenitis}

Vladimir T. Ivashkin¹, Igor V. Maev², Tatyana L. Lapina1, ${ }^{1}$, Evgeny D. Fedorov ${ }^{3}$, Arkadiy A. Sheptulin ${ }^{1}$, Aleksandr S. Trukhmanov ${ }^{1}$, Alexey V. Kononov ${ }^{4}$, Rustam A. Abdulkhakov ${ }^{5}$, Olga P. Alexeeva ${ }^{6}$, Sergey A. Alekseenko ${ }^{7}$,

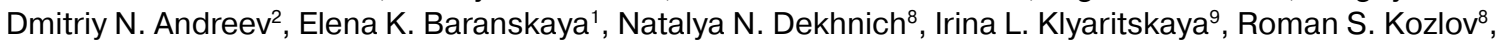
Evgenya A. Kogan ${ }^{1}$, Mikhail P. Korolev ${ }^{10}$, Natalya V. Korochanskaya ${ }^{11}$, Svetlana A. Kurilovich ${ }^{12}$, Maria A. Livsan ${ }^{4}$ Marina F. Osipenko ${ }^{12}$, Pavel V. Pavlov ${ }^{1}$, Sergey S. Pirogov ${ }^{13}$, Aiman S. Sarsenbaeva ${ }^{14}$, Vladimir I. Simanenkov ${ }^{15}$, Alexander S. Tertychny ${ }^{1}$, Aleksandr V. Tkachev ${ }^{16}$, Yury P. Uspensky ${ }^{10}$, Igor B. Khlynov ${ }^{17}$, Vladislav V. Tsukanov ${ }^{18}$

${ }^{1}$ Sechenov First Moscow State Medical University (Sechenov University), Moscow, Russian Federation

${ }^{2}$ Yevdokimov Moscow State University of Medicine and Dentistry, Moscow, Russian Federation

${ }^{3}$ Pirogov Russian National Research Medical University, Moscow, Russian Federation

${ }^{4}$ Omsk State Medical University, Omsk, Russian Federation

${ }^{5}$ Kazan State Medical University, Kazan, Russian Federation

${ }^{6}$ Privolzhsky Research Medical University, Nizhny Novgorod, Russian Federation

${ }^{7}$ Far-Eastern State Medical University, Khabarovsk, Russian Federation

${ }^{8}$ Smolensk State Medical University, Smolensk, Russian Federation

${ }^{9}$ Vernadsky Crimean Federal University, Simferopol, Russian Federation

${ }^{10}$ Saint-Petersburg State Pediatric Medical University, St. Petersburg, Russian Federation

${ }^{11}$ Kuban State Medical University, Krasnodar, Russian Federation

${ }^{12}$ Research Institute of Therapy and Preventive Medicine - branch of the Federal Research Center Institute of Cytology and Genetics of the Siberian Branch of the Russian Academy of Sciences, Novosibirsk, Russian Federation 


\author{
${ }^{13}$ Hertsen Moscow Oncology Research Center - Branch of the National Medical Research Radiology Center, Moscow, \\ Russian Federation \\ ${ }^{14}$ South Ural State Medical University, Chelyabinsk, Russian Federation \\ ${ }^{15}$ Mechnikov North-Western State Medical University, St. Petersburg, Russian Federation \\ ${ }^{16}$ Rostov State Medical University, Rostov-on-Don, Russian Federation \\ ${ }_{17}$ Ural State Medical University, Ekaterinburg, Russian Federation \\ ${ }^{18}$ Research Institute for Medical Problems in the North - Division of Krasnoyarsk Scientific Centre of Siberian Branch of the RAS, \\ Krasnoyarsk, Russian Federation
}

\begin{abstract}
Aim. The clinical guidelines are intended to supplement specialty decision-making for improved aid quality in patients with gastritis and duodenitis though acknowledging the latest clinical evidence and principles of evidencebased medicine.
\end{abstract}

Key points. Gastritis is an inflammatory disease of stomach mucosa, with a separate definition of acute and chronic gastritis. Chronic gastritis is a cohort of chronic diseases uniting a typical morphology of persistent inflammatory infiltration, impaired cellular renewal with emergent intestinal metaplasia, atrophy and epithelial dysplasia of gastric mucosa. Oesophagogastroduodenoscopy (OGDS) or high-resolution OGDS with magnified or non-magnified virtual chromoendoscopy, including targeted biopsy for atrophy and intestinal metaplasia grading and neoplasia detection, are recommended to verify gastritis and duodenitis, precancer states and/or gastric mucosal changes. All chronic gastritis patients positive for $H$. pylori should undergo eradication therapy as aetiological and subsidiary for gastric cancer prevention. Chronic gastritis patients with symptoms of dyspepsia (epigastric pain, burning and congestion, early satiety), also combined with functional dyspepsia, are recommended proton pump inhibitors, prokinetics, rebamipide and bismuth tripotassium dicitrate in symptomatic treatment. With focal restricted intestinal metaplasia, follow-up is not required in most cases, mainly when advanced atrophic gastritis is ruled out in high-quality endoscopy with biopsy. However, a familial history of gastric cancer, incomplete intestinal metaplasia and persistent $H$. pylori infection render endoscopy monitoring with chromoendoscopy and targeted biopsy desirable once in three years. Patients with advanced atrophic gastritis should have high-quality endoscopy every 3 years, and once in 1-2 years if complicated with a familial history of gastric cancer.

Conclusion. The recommendations condense current knowledge on the aetiology and pathogenesis of gastritis and duodenitis, as well as laboratory and instrumental diagnostic techniques, main approaches to aetiological $H$. pylori eradication and treatment of dyspeptic states.

Keywords: gastritis, duodenitis, Helicobacter pylori, dyspepsia, atrophy, metaplasia, dysplasia

Conflict of interest: the authors declare no conflict of interest.

For citation: Ivashkin V.T., Maev I.V., Lapina T.L., Fedorov E. D., Sheptulin A.A., Trukhmanov A.S., Kononov A.V., Abdulkhakov R.A., Alexeeva O.P., Alekseenko S.A., Andreev D.N., Baranskaya E.K., Dekhnich N.N., Klyaritskaya I.L., Kozlov R.S., Kogan E.A., Korolev M.P., Korochanskaya N. V., Kurilovich S.A., Livsan M.A., Osipenko M.F., Pavlov P.V., Pirogov S.S., Sarsenbaeva A.S., Simanenkov V.I., Tertychny A.S., Tkachev A.V., Uspensky Yu.P., Khlynov I.B., Tsukanov V.V. Clinical Recommendations of Russian Gastroenterological Association and RENDO Endoscopic Society on Diagnosis and Treatment of Gastritis and Duodenitis. Russian Journal of Gastroenterology, Hepatology, Coloproctology. 2021;31(4):70-99. https://doi.org/10.22416/1382-4376-2021-31-4-70-99

\section{1. Краткая информация по заболеванию или состоянию (группе заболеваний или состояний)}

1.1. Определение заболевания или состояния (группы заболеваний или состояний)

Гастрит - воспалительное заболевание слизистой оболочки желудка. Различают острый и хронический гастриты. Хронический гастрит - группа хронических заболеваний, которые морфологически характеризуются персистирующим воспалительным инфильтратом и нарушением клеточного обновления с развитием кишечной метаплазии, атрофии и эпителиальной дисплазии в слизистой оболочке желудка.

Хронический дуоденит характеризуется воспалительной инфильтрацией слизистой оболочки двенадцатиперстной кишки, желудочной метаплазией эпителия и нарушениями гистоархитектоники и в виде укорочения ворсинок и углубления крипт.

\section{2. Этиология и патогенез заболевания или состояния (группы заболеваний или состояний)}

Гастритические изменения представляют собой реакции слизистой оболочки желудка в ответ на различные эндогенные и экзогенные патогенные факторы. К основным изменениям, из которых складывается морфологическая картина хронического гастрита, относятся воспаление, атрофия, нарушение клеточного обновления, в том числе метаплазия и дисплазия.

Бактерия Helicobacter pylori, колонизирующая слизистую оболочку желудка, служит этиологическим фактором гастрита. Установление этиологического значения $H$. pylori сделало хронический гастрит четко очерченной и клинически значимой нозологической единицей - заболеванием с известной причиной, этапами патогенетического развития, определенным прогнозом и, наконец, определило возможности этиотропного лечения. 
B.J. Marshall и J.R. Warren, которым впервые удалось выделить культуру ранее неизвестного грамотрицательного микроорганизма из биоптатов желудка человека, уже в первой публикации, открывшей широкомасштабное изучение $H$. pylori, связали наличие этой бактерии с инфильтрацией полиморфно-ядерными лейкоцитами эпителия и собственной пластинки слизистой оболочки на фоне лимфоплазмоцитарной инфильтрации [1]. Способность $H$. pylori колонизировать слизистую оболочку желудка и вызывать острый, а затем хронический гастрит получила блестящее подтверждение в опытах по самозаражению, независимо проведенных В. Marshall (1985) и А. Morris (1987). Большое значение для изучения патогенетического значения H. pylori имеют эксперименты на животных: моделями, на которых удается воспроизвести геликобактерный гастрит и некоторые другие H. pylori-ассоциированные заболевания, служат мыши, монгольские песчанки, морские свинки, гнотобионтные поросята и приматы [2]. На модели монгольской песчанки воспроизведена парадигма канцерогенеза в желудке (каскад Корреа): хроническое воспаление, вызванное H. pylori, кишечная метаплазия, атрофия, дисплазия / интраэпителиальная метаплазия и инвазивная аденокарцинома. Разным авторам удавалось воспроизвести гастрит у человека после заражения добровольцев культурой H. pylori [2, 3].

Колонизацию слизистой оболочки и выживание H. Pylori в особой среде желудка обеспечивает целый ряд факторов. Уреаза, фермент, гидролизующий мочевину с образованием аммония и углекислого газа, имеет значение для нейтрализации кислоты в окружении микроорганизма. Жгутики позволяют бактерии «целенаправленно» двигаться в слое слизи над эпителием. Другие ферменты бактерии способны вызывать деградацию муцина. Около $10 \%$ H. pylori непосредственно контактируют с эпителием. Адгезия H. pylori с эпителиоцитами - сложный процесс, в котором участвует целый ряд поверхностных белков. Например, BabA (blood group antigen binding adhesion) - адгезин, который связывается c Le ${ }^{\mathrm{b}}$ ангигенами группы крови на эпителиоцитах; аллель гена этого адгезина - babA2 тесно ассоциирована с развитием язвенной болезни и рака желудка в некоторых популяциях [2, 4].

В геноме бактерии выделяют «островок патогенности» cag PAI, маркером которого служит ген cagA - «цитотоксин-ассоциированный ген А». Этот ген обнаруживается у 50-70\% штаммов H. pylori. Некоторые белки, которые кодирует cag PAI, служат для построения секреторной системы IV типа бактерии, благодаря которой $H$. pylori при прикреплении к эпителиоциту желудка вводит внутрь клетки хозяина CagA, пептидогликан, а возможно, и другие собственные молекулы. Белки H. pylori в эпителиоците «запускают» несколько сигнальных путей, результатом чего служат изменение цитоскелета клетки хозяина, нарушение межклеточных контактов, изменение пролиферации и апоптоза, а также провоспалительный эффект. Эпителиоциты желудка отвечают на присутствие $H$. pylori вы- $^{-}$ свобождением IL-8 и хемокина, экспрессируемого и секретируемого Т-клетками при активации (RANTES), что приводит к активной воспалительной реакции в слизистой оболочке. Около $50 \%$ штаммов H. pylori секретируют высокоиммуногенный белок - вакуолизирующий цитотоксин A (VacA), который, соответственно, вызывает вакуолизацию клеток in vitro, a in vivo его связывают с воспалением и апоптозом [2, 4]. Таким образом, колонизация $H$. pylori поддерживает персистенцию воспалительного инфильтрата в слизистой оболочке желудка. H. pylori-индуцированное воспаление приводит к атрофии - необратимой утрате желез желудка с замещением их фиброзной тканью или метаплазированным эпителием. Атрофический гастрит, особенно с поражением тела желудка и гипохлоргидрией, доказанно служит фактором риска аденокарциномы желудка [2, 5-8].

Патоморфологические данные, а также исследования с применением теста проницаемости сахарозы доказывают, что при гастритах, а также при функциональной диспепсии имеет место синдром повышенной эпителиальной проницаемости, выраженность которого коррелирует с активностью воспалительного процесса в слизистой оболочке желудка. H. pylori вносит вклад в возникновение этот синдрома, оказывая негативное влияние на структурные компоненты плотных контактов эпителиоцитов [9]. Таким образом, синдром повышенной эпителиальной проницаемости участвует в патогенезе гастрита, а медикаментозная терапия, оказывающая цитопротективный эффект, патогенетически обоснована [9].

В основе аутоиммунного гастрита лежат аутоиммунные механизмы, что подтверждается наличием антител против антигенов париетальных клеток и/или против внутреннего фактора, а также сочетанием гастрита с другими аутоиммунными заболеваниями (аутоиммунный тиреоидит, сахарный диабет I типа, витилиго и др.) [10-12].

Другие особые формы гастрита встречаются реже, характеризуются специальными этиологическими факторами или могут сопровождать другие заболевания. Лимфоцитарный гастрит может быть связан с глютеновой энтеропатией, эозинофильный гастрит протекает в рамках эозинофильного гастроэнтерита, гранулематозный гастрит ассоциируют с болезнью Крона, саркоидозом, васкулитами [7].

\section{3. Эпидемиология заболевания \\ или состояния (группы заболеваний или состояний)}

Инфекция H. pylori имеет глобальное значение и широко распространена, в том числе и в нашей стране, где по данным эпидемиологических исследований в различных регионах инфицированы более 65-92 \% взрослого населения [13-18]. 
Высокая частота $H$. pylori определяет высокую частоту хронического гастрита.

Согласно Статистическим материалам «Заболеваемость взрослого населения России в 2019 году» зарегистрировано более 538 тысяч взрослых с установленным впервые в жизни диагнозом «гастрит и дуоденит», и заболеваемость взрослых составила 462,0 : 100 000. Всего в 2019 году по обращаемости взрослого населения зарегистрировано более 700 тысяч случаев с диагнозом «гастрит и дуоденит». Таким образом, диагноз «гастрит» широко применяется в практике здравоохранения. Этот факт, с одной стороны, отражает высокую реальную частоту заболевания, но, с другой стороны, служит свидетельством субъективных и объективных трудностей как в интерпретации симптомов диспепсии, так и в доступности необходимых методов диагностики, в первую очередь видеоэндоскопии высокой четкости с электронной/ виртуальной хромоскопией и увеличением и патолого-анатомического исследования биоптатов слизистой оболочки желудка.

\section{4. Особенности кодирования заболевания или состояния (группы заболеваний или состояний) по Международной статистической классификации болезней и проблем, связанных со здоровьем}

\section{Гастрит и дуоденит (К29)}

К29.0 - Острый геморрагический гастрит Острый (эрозивный) гастрит с кровотечением К29.1 - Другие острые гастриты

К29.2 - Алкогольный гастрит

К29.3 - Хронический поверхностный гастрит К29.4 - Хронический атрофический гастрит Атрофия слизистой оболочки

К29.5 - Хронический гастрит неуточненный Хронический гастрит:

- антральный

- фундальный

К29.6 - Другие гастриты

Гастрит гипертрофический гигантский

Гранулематозный гастрит

Болезнь Менетрие

К29.7 - Гастрит неуточненный

К29.8 - Дуоденит

К29.9 - Гастродуоденит неуточненный

\section{5. Классификация заболевания \\ или состояния (группы заболеваний или состояний)}

В докладе Киотского консенсуса для хронического гастрита предложена классификация, в основу которой положен этиологический принцип [7]:

\section{Аутоиммунный гастрит. \\ Инфекционный гастрит:}

- гастрит, вызванный Helicobacter pylori,

- бактериальный гастрит (Helicobacter heilmannii, Enterococcus, Mycobacteria, вторичный сифилитический гастрит), флегмона желудка,

- вирусный гастрит (энтеровирус, иитомегаловирус, вирус Эпштейна - Барр),

- микотический гастрит (микормикоз, кандидоз, гистоплазмоз),

паразитарный гастрит (Cryptosporidium, Strongyloides stercorale).

Гастрит, вызванный внешними причинами:

- гастрит, вызванный лекарствами,

- алкогольный,

- радиационный,

химический,

вызванный билиарным рефлюксом,

- вызванный другими определенными внешними причинами.

Гастрит, вызванный специальными причинами:

- лимфоцитарный,

- болезнь Менетрие,

- аллергический,

- эозинофильный.

Гастрит, обусловленный другими классифицированными заболеваниями:

- при саркоидозе,

- при васкулите,

- при болезни Крона.

Сиднейская классификация хронического гастрита (1990), модифицированная в 1994 году в Хьюстоне, учитывает топографию поражения (тело желудка, антральный отдел) и морфологические изменения слизистой оболочки желудка (степень активности воспаления, выраженность воспаления, выраженность атрофии и метаплазии, наличие и степень колонизации $H$. pylori). Данные характеристики оцениваются с помощью визуально-аналоговой шкалы, полуколичественно по степени выраженности морфологического признака: норма (отсутствие признака), слабый, умеренный, выраженный. Применение визуальноаналоговой шкалы снизило субъективность оценки при характеристике гистологической картины [19]. Топография и гистологическая характеристика гастрита важны, так как фенотип гастрита определяет риск развития таких заболеваний, как язвенная болезнь двенадцатиперстной кишки, язвенная болезнь желудка и рак желудка [2, 4, 6, 7].

Стадия и степень атрофического гастрита и кишечной метаплазии (метапластической атрофии) служат индикаторами риска развития рака желудка [20-22]. Для того чтобы облегчить и по возможности стандартизировать определение прогноза хронического гастрита, в первую очередь оценку риска развития рака желудка, применяется несколько методик. Прогностическая система OLGA (Operative Link for Gastritis Assessment) использует визуально-аналоговую шкалу Сиднейской классификации. Для определения стадии гастрита соотносят гистологическую выраженность атрофии c ее топографией: стадия 0 означает минимальный риск канцерогенеза, а стадия IV, соответственно, - максимальный, в 5-6 раз превышающий 
показатели риска рака желудка в популяции [23, 24]. Российский пересмотр системы OLGA за счет визуализации с помощью пиктограмм значительно упрощает оценку атрофии (метапластической атрофии) слизистой оболочки желудка. Российский пересмотр OLGA-system одобрен III съездом Российского общества патологоанатомов [24] и утвержден Федеральной службой в сфере здравоохранения и социального развития (ФС № 2010/220 от 10.06.2010) [25]. Аналогичная по базовым принципам система OLGIM анализирует вместо атрофии кишечную метаплазию [26].

Bсе более широко используется эндоскопическая оценка распространенности атрофии слизистой оболочки желудка по Кимура - Такемото [27, 28] либо по модифицированной шкале EGA [29], а также эндоскопическая оценка выраженности кишечной метаплазии по шкале EGGIM [30].

Наличие острых и/или хронических эрозий желудка и двенадцатиперстной кишки следует указывать в эндоскопическом заключении или в диагнозе как отдельную позицию. Естественное течение и клиническое значение эрозивного гастрита или эрозивного дуоденита зависят от этиологии. Частыми причинами их возникновения служат нестероидные противовоспалительные препараты (НПВП), стресс, употребление алкоголя. Среди более редких причин называют лучевое поражение, вирусную инфекцию (например, цитомегаловирус), прямую травматизацию (например, назогастральный зонд) [7, 31].

\section{6. Клиническая картина заболевания \\ или состояния (группы заболеваний \\ или состояний)}

Под диспепсией понимают такие симптомы, как боль или жжение в эпигастральной области, переполнение в эпигастральной области, чувство раннего насыщения. Хронический гастрит, который характеризуется определенными морфологическими изменениями слизистой оболочки, часто не является причиной возникновения симптомов, в том числе диспептических. Однако у части больных с диспепсией имеющиеся клинические симптомы могут быть обусловлены хроническим H. pylori-ассоциированным гастритом, что доказывается стойким их исчезновением после эрадикации инфекта. Диспепсию, ассоциированную c H. pylori и хроническим гастритом, в докладе Киотского консенсуса предложено рассматривать как самостоятельную клиническую форму. Наоборот, персистенция диспептических симптомов, несмотря на успешно проведенную эрадикацию H. pylori, рассматривается как проявление функционального заболевания - функциональной диспепсии [7, 32].

Гастродуоденальные эрозии, в том числе обусловленные приемом НПВП, нередко протекают малосимптомно и могут манифестировать острым желудочно-кишечным кровотечением [7, 33].
Клиническую картину аутоиммунного гастрита обычно связывают с проявлениями дефицита витамина $\mathrm{B}_{12}$ (макроцитарная анемия, неврологическая симптоматика), железодефицитной анемией и сочетанными аутоиммунными заболеваниями [10-12]. Однако имеются исследования, которые позволяют говорить о наличии гастроэнтерологических симптомов у пациентов с аутоиммунным гастритом. Гастроэнтерологические симптомы зарегистрированы у 60 \% пациентов с аутоиммунным гастритом, причем представлены они в основном диспептическими симптомами, которые чаще наблюдались у пациентов моложе 55 лет, не курящих и без анемии [34]. В другом исследовании эпигастральная боль установлена в 35 \% случаев аутоиммунного гастрита, тошнота - в $22 \%$, раннее насыщение - в $10 \%$, тяжесть после еды в 7,1\%. Частыми симптомами оказались изжога (24\%) и регургитация (12 \%) [35]. С помощью рН-импедансометрии при аутоиммунном гастрите показано, что некислые рефлюксы могут быть ассоциированы с наличием симптомов [36].

\section{2. Диагностика заболевания или состояния (группы заболеваний или состояний), медицинские показания и противопоказания к применению методов диагностики}

\section{Критерии установления диагноза заболе- вания / состояния:}

Диагноз гастрита основан на гистологическом выявлении воспаления слизистой оболочки желудка (нейтрофильные лейкочиты в собственной пластинке и интраэпителиально, плотность мононуклеарной воспалительной инфильтрации), а также атрофии и кишечной метаплазии.

Современные методы эндоскопического исследования, в частности видеоэндоскопия высокой четкости с электронной/виртуальной хромоскопией и увеличением, предоставляют дополнительные высокоинформативные возможности для диагностики гастрита, дуоденита, предраковых изменений слизистой оболочки желудка.

Важнейшим этиологическим фактором гастрита служит инфекиия H. pylori, и положительные тесты на Н. pylori свидетельствуют о наличии хронического гастрита.

\section{1. Жалобы и анамнез}

Возможные жалобы у пациентов с гастритом и интерпретация данных жалоб представлены в подразделе 1.6.

При сборе анамнеза следует уточнить, проводилась ли ранее пациенту ЭГДС с биопсией; имелись ли при этом указания на наличие предраковых состояний и изменений слизистой оболочки желудка (атрофия, кишечная метаплазия, эпителиальная 
дисплазия). Для оценки прогноза важно уточнить, была ли ранее проведена эрадикационная терапия инфекции H. pylori, с помощью какой схемы лечения, проведен ли контроль эффективности антигеликобактерной терапии.

Для аутоиммунного гастрита важны указания в анамнезе на дефицит витамина $\mathrm{B}_{12}$ и макроцитарную анемию, наличие таких аутоиммунных заболеваний, как аутоиммунный тиреоидит, сахарный диабет I типа, витилиго и др., выявленную при ранее проведенном эндоскопическом и патолого-анатомическом исследовании атрофию слизистой оболочки тела желудка при относительно сохранной слизистой оболочке антрального отдела.

\section{2. Физикальное обследование}

При физикальном обследовании, как правило, нет данных, которые были бы характерны для гастрита.

\section{3. Лабораторные диагностические исследования}

- Всем пациентам с гастритом с целью исключения анемии из-за кровотечений при эрозивном поражении гастродуоденальной слизистой оболочки или из-за аутоиммунного гастрита рекомендуется выполнение общего (клинического) анализа крови с определением уровня гемоглобина, гематокрита, объема эритроцита, цветового показателя [35, 37-39].

Уровень убедительности рекомендаций $\mathrm{C}$ (уровень достоверности доказательств - 4)

Комментарии: Клинический анализ крови при хроническом гастрите чаще всего остается без существенных изменений, но может обнаруживаться анемия, как микрощитарная, свидетельствуюшая о явных либо скрытых кровотечениях или нарушении всасывания железа, так и макроцитарная вследствие дефицита витамина $B_{12}$ при аутоиммунном поражении желудка [35, 37-39].

- Всем пациентам с подозрением на аутоиммунный гастрит с целью подтверждения диагноза рекомендуется проведение анализа крови на антитела к париетальным клеткам и антитела к фактору Касла [10-12, 39-41].

Уровень убедительности рекомендаций В (уровень достоверности доказательств - 2)

Комментарии: Мишенью антител $\kappa$ париетальным клеткам служит $\mathrm{H}+/ \mathrm{K}+\mathrm{AT \Phi -аза}$ (альфа- и бета-субъединищы протонной помnы). Их выявляют у 85-90 \% больных c пернициозной анемией. Чувствительность для диагноза аутоиммунного гастрита составляет 80\%, специфичность низкая (обнаруживаются у лич без аутоиммунного гастрита). Антитела $к$ внутреннему фактору блокируют связывание кобаламина с внутренним фактором. Чувствительность для диагностики аутоиммунного гастрита 50 \%, но специфичность достигает $99 \%$ [10-12, 39-41].

- Всем пациентам с подозрением на наличие при гастрите предраковых изменений желудка (атрофии, кишечной метаплазии) с целью подтверждения диагноза, оценки степени риска развития рака желудка и определения порядка эндоскопического наблюдения рекомендуется проведение анализа крови на пепсиноген I, пепсиноген II и гастрин-17 [7, 42-47].

Уровень убедительности рекомендаций $\mathrm{A}$ (уровень достоверности доказательств - 2)

Комментарии: Диагноз атрофического гастрита стал более доступным благодаря сывороточным маркерам атрофии слизистой оболочки тела и антрального отдела желудка. Низкий уровень сывороточного пепсиногена I имеет высокую чувствительность и специфичность (84 и $95 \%$ соответственно) в диагностике выраженной атрофии слизистой оболочки тела желудка. Для атрофии слизистой оболочки антрального отдела характерны низкие уровни базального и постпрандиального гастрина-17 за счет уменьшения количества G-клеток.

При длительном наблюдении лич с нормальным сывороточным пепсиногеном, независимо от наличия H. pylori, частота развития рака желудка была незначительной. У лич с низким уровнем пепсиногена, свидетельствуюшим об атрофическом гастрите тела желудка, частота развития рака желудка было существенно выше (3,5-6 на 1000 в год). В данной группе заболеваемость раком желудка была больше при отрицательном результате антител $к$ H. pylori, что было связно с выраженной атрофией и метаплазией, препятствуюших дальнейшей колонизаuии H. pylori [44]. В исследовании, проведенном в Российской Федерачии, рак желудка был ассощиирован с низким уровнем пепсиногена I (omношение шансов (ОШІ) 2,9; $95 \%$ доверительный интервал (ДИ)1,3-6,4), низким соотношением пепсиногена I к пепсиногену II (ОШІ 3,3; $95 \%$ ДИ 1,5-7,3), низким уровнем гастрина-17 (ОШІ 1,8; $95 \%$ ДИ 0,7-4,8) [45]. Метаанализ 20 исследований, включавших 4241 пачиента, показал, что для диагноза атрофического гастрита сочетанная оченка сывороточного пепсиногена, гастрина-17 и антител класса IgGк H. pylori продемонстрировала чувствительность 74,7\% (95\% ДИ 62,0-84,3) и специфичность 95,6\% (95\% ДИ 92,6-97,4). Отрищательная предсказательная ценность составила $91 \%$ [42]. Метаанализ 31 исследования, включавшего 1520 пачиентов c аденокарииномой желудка и 2265 пачиентов с атрофическим гастритом, продемонстрировал, что сывороточный пепсиноген служит надежным неинвазивным скрининговым маркером рака желудка и предракового заболевания - атрофического гастрита [43]. 


\section{4. Инструментальные диагностические} исследования

- Всем пациентам с целью подтверждения диагноза гастрита и дуоденита, выявления и ранжирования предраковых состояний и изменений слизистой оболочки желудка, в первую очередь распространенности и степени атрофии, кишечной метаплазии и дисплазии, при отсутствии противопоказаний рекомендуется проведение эзофагогастродуоденоскопии (ЭГДС) [29, 30, 32, 37, 38, 46-49].

Уровень убедительности рекомендаций А (уровень достоверности доказательств - 2)

Комментарии: Для диагностики предраковых изменений желудка при традиционной эндоскопии в белом свете коррелячия между эндоскопическими и гистологическими данными неудовлетворительна [46], результать эндоскопии высокого разрешения более надежны. В многочентровых проспективных исследованиях специфичность эндоскопии высокого разрешения в белом свете для диагностики кишечной метаплазии составила $98 \%$, чувствительность - 53 и $59 \%$; для диагностики неоплазии спещифичность оказалась $>95 \%$, чувствительность - 74 и $29 \%$ [30, 49]. В метаанализе, включавшем 10 исследований и 699 пациентов, чувствительность, специфичность и площадь под кривой ( $A U C$ ) хромоэндоскопии с красителями для диагностики предраковых изменений и раннего рака желудка составили 0,90 (95\% ДИ 0,87-0,92), 0,82 (95\% ДИ 0,79-0,86) и 0,95 соответственно, что превосходит результаты эндоскопии в белом свете [48].

- Всем пациентам для диагностики предраковых состояний и/или изменений слизистой оболочки желудка при возможности рекомендуется выполнение ЭГДС высокого разрешения и виртуальной хромоэндоскопии с увеличением или без него, в том числе для выполнения прицельной биопсии с целью оценки стадии атрофии и кишечной метаплазии и выявления неоплазии [30, 34, 35, 43, 47, 49-51].

Уровень убедительности рекомендаций А (уровень достоверности доказательств - 2)

Комментарии: Систематический обзор показал, что эндоскопическое исследование в режиме NBI (в большинстве исследований с увеличением) для диагностики кишечной метаплазии продемонстрировало чувствительность и специфичность 86 и $77 \%$, а для диагностики дисплазии - 90 и $83 \%$ [49]. На основании воспроизводимых признаков эндоскопии в режиме NBI была предложена упрощенная классификачия изменений слизистой оболочки, точность диагностики кишечной метаплазии составила $84 \%$, дисплазии - $95 \%$. Отмечено, что представленные результаты зависят от подготовки и лучше y опытных эндоскопистов [50]. В проспективном многоцентровом исследовании с применением данной классификации чувствительность и специфичность для диагностики кишечной метаплазии составили 87 и $97 \%$, для диагностики дисплазии - 92 и $99 \%$ [30].

- Всем пациентам, у которых впервые проводится диагностическая ЭГДС, для адекватного стадирования предраковых состояний слизистой оболочки желудка у пациентов с подозрением на наличие атрофических, метапластических и неопластических изменений рекомендуется проведение биопсии (с последующим патолого-анатомическим исследованием биопсийного материала желудка, в том числе с применением гистохимических и иммуногистохимических методов), как для диагностики инфекции H. pylori, так и для идентификации стадий атрофического гастрита [52-59].

Уровень убедительности рекомендаций В (уровень достоверности доказательств - 2)

- Выполнение биопсии рекомендуется из двух отделов желудка (по два биоптата из тела и антрального отдела по малой и большой кривизне). Биоптаты из тела и антрального отдела желудка необходимо четко маркировать и помещать в отдельные контейнеры. Дополнительная биопсия должна быть взята из каждого видимого патологического участка слизистой оболочки желудка. Если для оценки тяжести атрофического гастрита планируется использование систем OLGA или OLGIM, возможно дополнительное взятие биопсии из угла желудка [52-57].

Уровень убедительности рекомендаций С (уровень достоверности доказательств - 4)

Комментарии: Диагноз «гастрит» традичионно рассматривается как диагноз морфологический. $B$ соответствии $c$ требованиями Модифицированной Сиднейской системы для правильной интерпретации состояния слизистой оболочки желудка необходимо минимум пять биоптатов. Определены места для получения биопсийного материала: 2 из антрального отдела на расстоянии 3 см от привратника по большой и малой кривизне, 2 из тела желудка посередине большой кривизны и на 4 см проксимальнее угла по малой кривизне, 1 - из угла желудка [19]. $B$ настоящее время хромоэндоскопия обеспечивает прецизионное взятие биопсии, что в сочетании c биопсией из фиксированных точек обеспечивает лучшую диагностику предраковых изменений. Биопсия из угла желудка позволяет более точно определять предраковые изменения, особенно в тех случаях, когда хромоэндоскопия и другие методь эндоскопии с расширенными возможностями недоступны. Биопсия из угла желудка позволяет более точно оченить стадии в соответствии с OLGA и OLGIM, которые коррелируют с риском развития рака желудка [46, 55-57].

\section{5. Иные диагностические исследования}

- Всем пациентам с гастритом с целью определения показаний к этиотропной эрадикационной терапии рекомендуется проведение тестирования 
на наличие инфекции с помощью ${ }^{13} \mathrm{C}$-уреазного дыхательного теста на Helicobacter pylori или определения антигена $H$. pylori в кале, а при проведении ЭГДС - с помощью быстрого уреазного теста [6, 58-66].

Уровень убедительности рекомендаций В (уровень достоверности доказательств - 2)

Комментарии: $B$ соответствии с рекомендациями согласительного совещания «Маастрихт-V》 (2016) [6] наиболее оптимальными тестами первичной диагностики инфекции Н. pylori служат ${ }^{13} \mathrm{C}$-дыхательный уреазный тест и определение антигена Н. pylori в кале. Так, согласно последнему Кокрейновскому обзору и метаанализу чувствительность ${ }^{13} \mathrm{C}$-дыхательного уреазного теста составляет 94 \% (95\% ДИ: 0,89-0,97), а определение антигена H. pylori в кале - 83\% (95\% ДИ: 0,73-0,90) при спещифичности в $90 \%$ [60].

При проведении ЭГДС методом первичной диагностики может быть быстрый уреазный тест. При использовании эндоскопических методов диагностики Н. pylori берут, как минимум, 2 биоптата из тела желудка и 1 биоптат из антрального отдела [58, 59, 63-65]. Серологический метод выявления антител класca IgG к H. pylori также может применяться для первичной диагностики инфекции H. pylori [59]. Микробиологический (бактериологический) метод (микробиологическое (культуральное) исследование биоптатов слизистой желудка на $H$. pylori с определением чувствительности к антибактериальным препаратам) применяется в настоящее время для определения индивидуальной чувствительности бактерии в случаях неэффективности лечения [6, 58, 59, 66].

Для контроля эрадикачии, который проводят через 4-6 недель после окончания эрадикачионной терапии, лучше всего применять ${ }^{13}$ С-уреазный дыхательный тест или определение антигена H. pylori в кале. Во избежание ложноотрицательных результатов прием ИПП необходимо прекратить за 2 недели до предполагаемого контрольного исследования. Кроме того, отрицательный результат исследования на инфекцию Н. pylori должен быть обязательно подтвержден другим методом диагностики [66].

\section{3. Лечение, включая}

медикаментозную

и немедикаментозную терапии, диетотерапию, обезболивание, медицинские показания

\section{и противопоказания к применению методов лечения}

\section{1. Медикаментозное лечение}

- Всем пациентам с хроническим гастритом c положительными результатами тестирования на инфекцию H. pylori в качестве этиологического лечения рекомендуется проведение эрадикационной терапии [3, 7, 66-72].

- Уровень убедительности рекомендаций В (уровень достоверности доказательств - 2)

- Всем пациентам с атрофическим гастритом c положительными результатами тестирования на инфекцию $H$. pylori для предотвращения прогрессирования атрофии рекомендуется проведение эрадикационной терапии [6, 7, 66, 73-75].

Уровень убедительности рекомендаций $\mathrm{A}$ (уровень достоверности доказательств - 2)

Комментарии: H. pylori служит этиологическим фактором хронического гастрита. Эрадикационная терапия инфекции позволяет излечить неатрофический гастрит, что сопровождается хорошо изученными гистологическими изменениями: в ранние сроки исчезает инфильтрация эпителия и собственной пластинки слизистой оболочки полиморфно-ядерными лейкоцитами; инфильтрация лимфочитами u плазматическими клетками снижается в достаточно ранние сроки, но не исчезает полностью более года после эрадикачии; лимфоидные фолликулы также сохраняются более года после этиологического лечения, хотя число их и сокрашается [67-72]. По итогам нескольких метаанализов установлено, что в результате эрадикачионной терапии Н. pylori происходит регрессия или, как минимум, стабилизачия атрофии слизистой оболочки в теле и антральном отделе желудка, при этом возможно добиться только стабилизачии, но не обратного развития кишечной метаплазии [73-75].

В качестве схемь первой линии служит стандартная тройная схема эрадикачионной терапии, включающая в себя ИПН (в стандартной дозе (\#омепразол** 20 мг. пантопразол 40-20 мг, рабепразол 20 мг, \#эзомепразол** 20 мг) 2 раза в сутки ), кларитромичин** ( по 500 мг 2 раза в сутки) амоксищиллин** (по 1000 мг 2 раза в сутки) [6, 66, 76-78]. Стандартную тройную терапию следует назначать, применяя различные меры, повышаюшие ее эффективность (см. ниже) [6, 66].

Как вариант эрадикационной терапии первой линии (например, при непереносимости препаратов группь пеничиллина (АTX - бета-лактамные антибактериальные препараты: пенициллины)) может быть назначена классическая четырехкомпонентная схема на основе висмута трикалия дицитрата** (120 мг 4 раза в сутки) в комбинации с ИПН (в стандартной дозе 2 раза в сутки), \#тетрациклином** (500 мг 4 раза в сутки), метронидазолом** (по 500 мг 3 раза в сутки) [6, 66, 79, 80].

Квадротерапия с висмута трикалия дищитратом** применяется также как основная схема терапии второй линии при неэфрективности стандартной тройной терапии [6, 66, 81]. 
Другой схемой терапии второй линии служит эрадикачионная схема, включающая в себя ИПН (в стандартной дозе 2 раза в сутки (\#омепразол** 20 мг. пантопразол 20 мг, рабепразол 20 мг, \#эзомепразол** 20 мг)), \#левофлоксаиин ** (в дозе 500 мг 2 раза в сутки) и амоксициллин** (в дозе 1000 мг 2 раза в сутки) [81-83]. Тройная терапия с \#левофлоксацином** может быть назначена только врачом-гастроэнтерологом по взвешенным показаниям [6, 66].

Терапия третьей линии подбирается индивидуально в зависимости от выбора предшествующих схем лечения, при возможности по данным определения чувствительности Н. pylori $\kappa$ антибиотикам [6, 66].

$B$ «Рекомендачиях Российской гастроэнтерологической ассочиачии по диагностике и лечению инфекции Helicobacter pylori у взрослых» были перечислены меры, повышаюшие эффективность эрадикационной терапии [66]. Очевидно, что эти меры должны быть универсальными и применимыми в любой линии терапии, а комбинирование этих мер позволяет добиться наилучшего результата у конкретного пащиента.

Меры, повышающие эффективность эрадикационной терапии:

1. Продолжительность всех схем лечения H. pylori должна составлять 14 дней, минимальная продолжительность 10 дней может быть назначена в тех случаях, если исследования, проведенные в данном регионе, подтвердили ее высокую эффрективность. Увеличение продолжительности лечения имеет универсальный характер, так как положительный эффект наблюдается при всех изученных режимах антигеликобактерного лечения, в том числе при стандартной тройной терапии [6, 66, 84, 85].

2. Назначение высокой дозы ИПН (удвоенной по сравнению со стандартной) способствует повышению эффективности лечения. При проведении эрадикационной терапии предпочтение отдается \#эзомепразолу** (20 мг 2 раза в сутки) и рабепразолу (20 мг 2 раза в сутки) [6, 66, 86-88].

3. Добавление $к$ стандартной тройной терапии висмута трикалия дицитрата** в дозе 240 мг 2 раза в сутки или 120 мг 4 раза в сутки служит мерой повышения ее эффективности [66, 80, 89, 90].

4. Включение пробиотических итаммов, доказавших свою эффективность в клинических исследованиях, в состав эрадикачионной терапии Н. pylori приводит к повышению эффрективности эрадикации и снижению числа нежелательных явлений [6, 66, 91-94].

5. Включение ребамипида в дозе 100 мг 3 раза в сутки в состав эрадикационной терапии H. pylori приводит к повышению эффективности эрадикации [66, 95].

6. Подробное инструктирование пачиента и контроль за точным соблюдением назначенного режима приема лекарственных средств приводит к повышению эфрективности эрадикаионной терапии [6, 66].

- Пациентам с эрозивным гастритом и дуоденитом, в том числе на фоне приема нестероидных противовоспалительных препаратов, с целью достижения заживления эрозий рекомендуется проведение антисекреторной терапии ингибиторами протонного насоса в течение 4-6 недель [96-100] или ребамипидом в течение 4-8 недель [101, 102].

Уровень убедительности рекомендаций В (уровень достоверности доказательств - 2)

Комментарии: Базисная антисекреторная терапия с применением ИПН (назначение омепразола** в суточной дозе 20 мг, лансопразола 30 мг, пантопразола 40 мг, \# \#рабепразола 20 мг, \#эзомепразола** 20 мг на 2-4 недели, при необходимости на более длительный срок, служит основным методом лечения гастродуоденальных эрозий, в том числе индуцированных нестероидными противовоспалительными препаратами [96-100, 103]. Эффективность ребамипида для заживления эрозивного гастрита доказана в клинических исследованиях в том числе рандомизированных [101, 102].

- Пациентам с хроническим гастритом, в том числе атрофическим, с целью потенцирования защитных свойств слизистой оболочки возможно рекомендовать терапию висмута трикалия дицитратом** $[66,104,105]$ или ребамипидом в течение 4-8 недель [6, 66, 106-111].

Уровень убедительности рекомендаций В (уровень достоверности доказательств - 2)

Комментарии: Цитопротективный эффект висмута трикалия дицитрата** обусловлен связыванием ионами висмута свободных радикалов и усилением эндогенного синтеза простагландинов [105], в когортном исследовании продемонстрировано снижение уровня повреждения ДНК генеративной зоны слизистой оболочки желудка пациентов после успешной эрадикащии H. pylori на фоне четырехнедельной терапии висмута трикалия дицитратом** [104]. Ребамипид оказывает защитный эффект на слизистую оболочку желудочно-кишечного тракта за счет регуляиии уровня простагландинов, восстановления физиологической продукиии слизи и плотных контактов, а также ингибирования продуктов окислительного стресса, провоспалительных иитокинов и хемокинов, что в комплексе ведет $\kappa$ устранению синдрома повышенной пронииаемости слизистых оболочек [9, 110, 111]. В рандомизированных контролируемых исследованиях ребамипид привел к уменьшению воспаления, а в одном исследовании даже к уменьшению кишечной метаплазии и дисплазии низкой степени, способствовал профилактике рака желудка у паииентов высокого риска [106-109].

- Пациентам с хроническим гастритом и симптомами диспепсии (особенно такими, как боль 
и жжение в эпигастрии), в том числе в сочетании c функциональной диспепсией, в качестве симптоматического лечения рекомендуется проведение терапии ингибиторами протонного насоса [32, 112-114].

Уровень убедительности рекомендаций А (уровень достоверности доказательств - 1)

Комментарии: Гиперчувствительность к кислоте, снижение клиренса двенадиатиперстной кишки и изменение перистальтики желудка, индуцированное кислым рефлюксом из двенадиатиперстной кишки, служат обоснованием назначения кислотосупрессивной терапии при функциональной диспепсии, особенно при синдроме эпигастральной боли [32, 114, 115]. Метаанализ 8 РКИ с участием 2216 пачиентов с ФД показал, что ИПП были более эффективными, чем плачебо, для улучшения симптомов, причем улучшение симптомов наблюдалось у 36,0 \% в группе ИПН и 30,0 \% в группе плачебо (относительный риск (ОР ) 1,41; $95 \%$ дИ 1,07-1,87). Число больных, которых необходимо лечить (NNT), составило 9 (95\% ДИ, 6-24). ИПН оказались эффективными с точки зрения облегчения симптомов (ОР 1,44; $95 \%$ ДИ 1,03-2,01) и полного купирования симптомов (ОР 1,26; $95 \%$ ДИ 1,07-1,49) [114].

- Пациентам с хроническим гастритом и симптомами диспепсии (особенно такими, как переполнение в эпигастрии и раннее насыщение), в том числе в сочетании с функциональной диспепсией, в качестве симптоматического лечения рекомендуется проведение терапии препаратами, обладающими прокинетическим эффектом [32, 114-118].

Уровень убедительности рекомендаций В (уровень достоверности доказательств - 1)

Комментарии: Тримебутин - средство, действующее на энкефалинергическую систему желудочно-кишечного тракта и таким образом нормализующее его моторику, в РКИ продемонстрировал высокую эффективность для купирования таких симптомов диспепсии, как тяжесть после еды, быстрое насыщение, абдоминальная боль у пачиентов с ФД, а также у пачиентов с ФД в сочетании с синдромом раздраженного кишечника [119, 120]. Способность тримебутина купировать симптомы диспепсии подтверждена в масштабных проспективных неинтервенционных исследованиях, проведенных в РФ, общее число участников которых составило 4533 человека $[121,122]$. Сцинтиграфия с коллоидной полутвердой пищей, меченной ${ }^{99} \mathrm{mTc}$-Tin, показала, что тримебутин нормализует опорожнение желудка [120]. По данным сетевого метаанализа, посвященного оченке препаратов с прокинетическим действием при функииональной диспепсии, тримебутин продемонстрировал сопоставимую c метоклопрамидом** и домперидоном эффективность по показателю поверхности под кумулятивной кривой распределения (surface under the cumulative ranking curve - SUCRA) [116].
При этом безопасность тримебутина по данным метаанализов не отличалась от плачебо $[116,123]$.

Итоприд по механизму действия одновременно является антагонистом дофаминовых рецепторов и блокатором ацетилхолинэстеразы. Препарат активирует освобождение ащетилхолина и препятствует его деградащии. Результаты крупного РКИ свидетельствовали о том, что через 8 недель лечения клинические симптомы диспепсии полностью исчезли или значительно уменьшилась их выраженность у 57 , 59 и 64 \% больных, получавших итоприд (соответственно в дозах 50, 100 и 200 мг 3 раза в сутки), что достоверно превышало эффрект плачебо (41%) [124]. Эффективность итоприда подтверждена и в других исследованиях, проведенных в том числе в России [125, 126]. Метаанализ 9РКИ, включавших 2620 больных с ФД, свидетельствовал о достоверно более высокой эффективности итоприда в отношении улучшения общего состояния, уменьшения тяжести в эпигастральной области после еды и раннего насыщения. Частота возникновения побочных эффектов была одинаковой в группах итоприда и плацебо [117].

Домперидон, по механизму действия являющийся антагонистом дофаминовых рецепторов, в метаанализе продемонстрировал эффективность в уменьшении симптомов диспепсии (OP 7,0 (95\% ДИ 3,6-16) [118]. Однако такие нежелательные явления, как увеличение интервала $Q-T$ и связанный с этим риск возникновения нарушений ритма сердиа (особенно при одновременном приеме препаратов, метаболизирующихся, как и домперидон, с помощью системы СУРЗА4), привели к ограничению показаний к назначению домперидона и продолжительности лечения [32]. В этой связи интерес представляет комбинированный препарат Домперидон + Омепразол (фиксированная комбинащия омепразола 20 мг и домперидона модифицированного высвобождения 30 мг). Клиническая эффективность обеспечивается потенцированием действия препаратов разных фармакологических групп, высоким комплаенсом (однократный прием в течение суток). Домперидон с модифицированным освобождением позволяет принимать препарат один раз в день вместо трехразового приема. При этом отсутствуют пиковые значения концентраций домперидона, возможные при использовании его обычных лекарственных форм, что снижает вероятность проявления нежелательных дозозависимых явлений. Кониентрачия домперидона в плазме крови на фоне применения фиксированной комбинащии омепразола 20 мг с домперидоном модифищированного высвобождения 30 мг не выходит за пределы однократной дозы 10 мг, что позволяет назначать препарат для курсового лечения симптомов диспепсии [127]. 
- Пациентам с хроническим гастритом и симптомами диспепсии для купирования этих симптомов рекомендуется лечение \#ребамипидом (100 мг 3 раза в сутки в течение 2-4 недель, при необходимости 8 недель) как в монотерапии, так и в составе комплексного лечения [128].

Уровень убедительности рекомендаций $\mathrm{A}$ (уровень достоверности доказательств - 1)

Комментарии: Согласно метаанализу 17 РКИ ребамипид достоверно уменьшает симптомы диспепсии не только при функциональной диспепсии, но и при гастрите, индуцированном НПВП [128].

\section{2. Эндоскопическое лечение}

- Пациентам с хроническим гастритом при обнаружении эндоскопически видимых патологических участков дисплазии низкой или высокой степени, а также раннего рака показано определение стадии процесса и соответствующее лечение, в том числе эндоскопическая резекция единым блоком [46, 47, 129, 130].

Уровень убедительности рекомендаций А (уровень достоверности доказательств - 2)

Комментарии: Дисплазия эпителия представляет собой гистологически однозначный неопластический эпителий (клеточный атипизм, нарушение гистоархитектоники) без достоверных признаков инвазии и служит предпоследней стадией каниерогенеза желудка [131, 132]. При наблюдении за пачиентами с дисплазией высокой степени в течение 4-48 месяцев доля пациентов с развитием рака или метахронным раком составила 60-85\%; при наблюдении за пачиентами с дисплазией низкой степени в течение 10-48 месяцев развитие рака наблюдалось в 0-23\% случаев [130]. Метаанализ показывает, что при проведении биопсии при дисплазии низкой степени после патолого-анатомического исследования диагноз дисплазии высокой степени устанавливают в $25 \%$ случаев, диагноз рака в $7 \%$ [129]. Таким образом, при выявлении патологического участка эпителиальной дисплазии взятие биоптатов малоэффективно для точного диагноза и эндоскопическое лечение служит тактикой выбора.

\section{4. Медицинская реабилитация и санаторно-курортное лечение, медицинские показания \\ и противопоказания к применению методов реабилитации, в том числе основанных на использовании природных лечебных факторов}

- Пациентам с хроническим гастритом в стадии ремиссии рекомендуется санаторно-курортное лечение [133].
Уровень убедительности рекомендаций С (уровень достоверности доказательств - 5)

Комментарии: На санаторно-курортное лечение не направляют пачиентов с противопоказаниями к курортному лечению, а также $\kappa$ проведению любых бальнеологических прочедур (например, пачиенты с болезнью Менетрие, c полипозом желудка и новообразованиями желудка). Следует обязательно учитывать возраст и наличие сопутствуюших заболеваний, что определяет выбор климатического региона. Ведущими методами санаторно-курортного этапа реабилитации служат немедикаментозные: естественные природные факторы (климат, минеральная вода, лечебная грязь), искусственно моделированные природные факторы, кинезотерапия (разнообразные формы и средства ЛФК, медииинский массаж), психотерапия, диетотерапия, фитотерапия и другие. Реабилитащия пачиентов на санаторном этапе происходит в соответствии с режимами - щадящим, тонизирующим и тренирующим, которые выбираются в зависимости от времени пребывания в санатории, характера заболевания и адаптаиионных возможностей организма. Больным хроническим гастритом со сниженной секреторной функцией желудка назначают питьевые среднеи высокоминерализованные хлоридно-натриевые, гидрокарбонатные натриевые воды (курорты Бобруйск, Горячий Ключ, Ессентуки, Нальчик, Старая Русса, Усть-Качка, Юрмала и др.). С иелью стимулящии секрещии желудочного сока и соляной кислоты минеральную воду назначают за 15-20 минут до едь 3 раза в день. Больным хроническим гастритом с повышенной секреторной функиией желудка назначают питьевые слабо- и среднеминерализованные углекислье гидрокарбонатные натриевые, натриево-кальциевые, сульфатные кальииево-магниево-натриевыми воды (Боржоми, Березовские минеральные воды, Дарасун, Железноводск, Ижевские минеральные водь и др.). Минеральную воду назначают за 1-1,5 часа до еды 3 раза в день [133].

\section{5. Профилактика и диспансерное наблюдение, медицинские показания и противопоказания к применению методов профилактики}

- Всем лицам с наличием инфекции H. pylori при отсутствии противопоказаний рекомендуется проведение эрадикационной терапии с целью профилактики рака желудка $[6-8,46,47,66$, 134-138].

Уровень убедительности рекомендаций А (уровень достоверности доказательств - 2)

Комментарии: Эрадикаџия инфекции H. pylori признана основным методом профилактики рака желудка, эффективность которого доказана 
в ряде популяционных исследований и в метаанализах [134-138]. В метаанализе 7 РКИ, включавшем 8323 человека, эрадикащия H. pylori снизила заболеваемость раком желудка по сравнению с лицами, которые не получали эрадикационную терапию, с показателем относительного риска 0,54(95\% ДИ 0,40-0,72; NNT = 72), а также смертность от рака желудка с показателем относительного риска 0,61 (95\% ДИ 0,40-0,92; $N N T=135)[135]$.

- Всем пациентам, которые перенесли эндоскопическую резекцию аденомы / раннего рака желудка, рекомендуется эрадикационная терапия H. pylori для профилактики метахронного рака желудка [6-8, 46, 47, 66, 135, 139-142].

Уровень убедительности рекомендаций В (уровень достоверности доказательств - 1)

Комментарии: Снижение частоты метахронного рака желудка у пачиентов после эрадикации H. pylori по сравнению с группой с персистениией инфекиии доказано в РКИ и метаанализах [135, 139-141]. Так, в метаанализе 3 исследований, включавшем 1841 пачиента с эндоскопической резекцией эпителиальной дисплазии / неоллазии, эрадикационная терапия снизила заболеваемость раком желудка с показателем относительного риска 0,49 (95\% ДИ 0,34-0,70, NNT = 21) $[135]$.

- Пациентам с выявленной дисплазией слизистой оболочки желудка в отсутствие видимого при эндоскопии отграниченного новообразования рекомендуется незамедлительно выполнить повторное эндоскопическое исследование высокого разрешения $\mathrm{c}$ хромоэндоскопией (виртуальной или с использованием красителей). В случае если при проведении повторного исследования вновь не удается выявить отграниченное новообразование, рекомендуется выполнить биопсию для определения стадии гастрита (если это не сделано ранее) и контрольное эндоскопическое исследование не позднее чем через 6 месяцев (при дисплазии высокой степени) и не позднее чем через 12 месяцев (при дисплазии низкой степени) [46, 47, 143-150].

Уровень убедительности рекомендаций С (уровень достоверности доказательств - 5)

- Пациентам со слабой и умеренной степенью атрофии слизистой оболочки, ограниченной только антральным отделом желудка, после успешной эрадикационной терапии $H$. pylori эндоскопическое наблюдение не рекомендуется [46, 47, 143-150].

Уровень убедительности рекомендаций В (уровень достоверности доказательств - 3)

- Пациентам с кишечной метаплазией, ограниченной одной анатомической областью, в большинстве случаев не рекомендуется наблюдение, особенно если высококачественное эндоскопическое исследование с биопсией позволило исключить выраженные стадии атрофического гастрита. Однако при наличии у таких пациентов отягощенного по раку желудка семейного анамнеза, неполной кишечной метаплазии, персистенции инфекции H. pylori рекомендуется эндоскопическое наблюдение с хромоэндоскопией и прицельной биопсией 1 раз в 3 года [46, 47, 143-152].

Уровень убедительности рекомендаций В (уровень достоверности доказательств - 3)

Пациентам с выраженным атрофическим гастритом (выраженная атрофия и/или кишечная метаплазия и в теле, и в антральном отделе желудка - OLGA/OLGIM III/IV) рекомендуется высококачественное эндоскопическое наблюдение каждые 3 года. Пациентам с выраженным атрофическим гастритом с отягощенным наследственным анамнезом по раку желудка рекомендуется эндоскопическое наблюдение 1 раз в 1-2 года [46, 47, 143-152]. Согласно приказу Министерства здравоохранения РФ от 29 марта 2019 г. № 173н «Об утверждении порядка проведения диспансерного наблюдения за взрослыми» диспансерное наблюдение при хроническом атрофическом фундальном и мультифокальном гастрите предусматривает прием (осмотр, консультация) врача-гастроэнтеролога 1 раз в год, прием (осмотр, консультация) врачаонколога по медицинским показаниям с контролируемым показателем стабилизации морфологических изменений по данным ЭГДС с биопсией.

Уровень убедительности рекомендаций В (уровень достоверности доказательств - 3)

Комментарии: Для определения интервалов эндоскопического наблюдения предложена стратификация пачиентов на основании выраженности предраковых изменений желудка и наличия дополнительных факторов риска рака желудка. Очевидно, что лича с выраженной атрофией u кишечной метаплазией слизистой оболочки желудка продолжают нуждаться в эндоскопическом наблюдении даже несмотря на ликвидащию инфекции H. pylori в результате успешной ее терапии [6-8, 46, 47, 142]. Популящионное исследование (405 172 человека за период 1979-2011 г2) показало, что у лии, которые проходили эндоскопическое исследование с биопсией в связи с неонкологическими показаниями, в течение 20 лет рак желудка развивается в одном случае из 256 с нормальной слизистой оболочкой желудка, в 1 из 85 с гастритом, в 1 из 50 с атрофическим гастритом, в 1 из 39 с кишечной метаплазией и в 1 случае из 19 с дисплазией [143]. В когортном исследовании при наблюдении 1755 пащиентов с диспепсией в среднем в течение 55 месящев неоплазия была выявлена исключительно у лич, с исходными стадиями OLGAIII-IV. Риск неоплазии отсутствовал у пачиентов со стадией OLGA 0, I и II (95\% ДИ 0-0,4), составил 36,5 на 1000 человеко-лет при стадии III (95\% ДИ 13,7-97,4) и 63,1 на 1000 человеко-лет при стадии IV (95 \% ДИ 20,3-195,6) [144]. Стадии 
OLGA III/IV и OLGIM I-IV оказались независимыми факторами риска рака желудка, причем даже незначительно выраженная кишечная метаплазия существенно повышала риск рака желудка [145, 146]. Данные исследования показывают, что наличие кишечной метаплазии (как маркера выраженного гастрита) может иметь даже большее значение, чем степень атрофии без кишечной метаплазии, поскольку риск рака желудка был выше с OLGIM I/II, чем с OLGA III / IV. Неполная кишечная метаплазия - прогностически неблагоприятный фактор развития рака желудка по сравнению с полной кишечной метаплазией, ее следует рассматривать как дополнительное условие определения сроков наблюдения пачиентов с гастритом [148-150]. Дополнительным фактором риска рака желудка служит наличие близких родственников, страдаюших раком желудка [151, 152].

- Пациентам с аутоиммунным гастритом рекомендуется эндоскопическое наблюдение 1 раз в 1-2 года [46, 47].
Уровень убедительности рекомендаций С (уровень достоверности доказательств - 5)

Комментарии: Аутоиммунный гастрит является предраковым заболеванием, что оправдывает эндоскопическое наблюдение. Так, относительный риск рака желудка при пернициозной анемии составил 6,8 (95\% ДИ 2,6-18,1). Недостатком этого метаанализа служит включение любых паииентов с низким уровнем витамина $B_{12}$, причиной которого служит не только аутоиммунный гастрит [153]. Через 3 года после первичного скринингового обследования у 56 пачиентов были выполнены контрольные ЭГДС, в ходе которых было выявлено 2 пачиента с аденокарчиномой желудка, ни одного пациента с дисплазией высокой степени и 49 пациентов с кишечной метаплазией [154]. В другом исследовании в течение 6-7 лет не было выявлено случаев рака желудка [155]. Согласно приказу Министерства здравоохранения РФ от 29 марта 2019 2. № 173н «Об утверждении порядка проведения диспансерного наблюдения за взрослыми» диспансерное

Критерии оценки качества медицинской помощи

\begin{tabular}{|c|c|c|c|}
\hline № & Критерии качества & $\begin{array}{c}\text { Уровень } \\
\text { достоверности } \\
\text { доказательств }\end{array}$ & $\begin{array}{c}\text { Уровень } \\
\text { убедительности } \\
\text { рекомендаций }\end{array}$ \\
\hline 1 & $\begin{array}{l}\text { Проведена ЭГДС, причем для диагностики предраковых изменений } \\
\text { и раннего рака желудка - видеоЭГДС высокого разрешения } \\
\text { с виртуальной хромоэндоскопией }\end{array}$ & A & 2 \\
\hline 2 & Взята биопсия при проведении диагностической ЭГДС & A & 2 \\
\hline 3 & $\begin{array}{l}\text { Проведено тестирование на наличие инфекции с помощью } \\
{ }^{13} \text { С-дыхательного уреазного теста на Helicobacter pylori или опре- } \\
\text { деления антигена H. pylori в кале, а при проведении ЭГдС - с по- } \\
\text { мощью быстрого уреазного теста с целью определения показаний } \\
\text { к этиотропной эрадикационной терапии }\end{array}$ & A & 1 \\
\hline 4 & $\begin{array}{l}\text { Проведена эрадикационная терапия при положительном результате } \\
\text { тестирования на инфекцию H. pylori в качестве этиологического } \\
\text { лечения }\end{array}$ & $\mathrm{B}$ & 2 \\
\hline 5 & $\begin{array}{l}\text { Проведена эрадикационная терапия при положительном результате } \\
\text { тестирования на инфекцию H. pylori пациентам с атрофическим } \\
\text { гастритом для предотвращения прогрессирования атрофии }\end{array}$ & A & 1 \\
\hline 6 & $\begin{array}{l}\text { Проведено соответствующее лечение, в том числе эндоскопиче- } \\
\text { ская резекция единым блоком при обнаружении эндоскопически } \\
\text { видимых патологических участков дисплазии низкой или высокой } \\
\text { степени, а также раннего рака }\end{array}$ & A & 1 \\
\hline 7 & $\begin{array}{l}\text { Проведена эрадикация инфекции } H . \text { pylori пациенту после эндоско- } \\
\text { пической резекции аденомы / раннего рака желудка для профилак- } \\
\text { тики метахронного рака желудка }\end{array}$ & $\mathrm{B}$ & 1 \\
\hline 8 & $\begin{array}{l}\text { Проведено эндоскопическое наблюдение } 1 \text { раз в } 3 \text { года пациен- } \\
\text { там с кишечной метаплазией, ограниченной одной анатомической } \\
\text { областью, при наличии у таких пациентов отягощенного по раку } \\
\text { желудка семейного анамнеза, неполной кишечной метаплазии, пер- } \\
\text { систенции инфекции } H \text {. pylori }\end{array}$ & $\mathrm{B}$ & 2 \\
\hline 9 & $\begin{array}{l}\text { Проведено высококачественное эндоскопическое наблюдение } \\
\text { каждые } 3 \text { года пациентам с выраженным атрофическим гастритом } \\
\text { (выраженная атрофия и/или кишечная метаплазия и в теле, и в ан- } \\
\text { тральном отделе желудка - OLGA/OLGIM III/IV) и эндоско- } \\
\text { пическое наблюдение } 1 \text { раз в } 1-2 \text { года пациентам с выраженным } \\
\text { атрофическим гастритом с отягощенным наследственным анамнезом } \\
\text { по раку желудка }\end{array}$ & $\mathrm{C}$ & 3 \\
\hline
\end{tabular}


Medical aid quality assessment criteria

\begin{tabular}{|c|c|c|c|}
\hline No. & Quality criteria & $\begin{array}{l}\text { Strength of } \\
\text { evidence level }\end{array}$ & $\begin{array}{l}\text { Credibility of recom } \\
\text { mendation level }\end{array}$ \\
\hline 1 & $\begin{array}{l}\text { OGDS, high-resolution video OGDS with virtual } \\
\text { chromoendoscopy for diagnosis of precancer lesions and early } \\
\text { gastric cancer }\end{array}$ & A & 2 \\
\hline 2 & Diagnostic OGDS with biopsy & A & 2 \\
\hline 3 & $\begin{array}{l}\text { Helicobacter pylori diagnosis for deciding aetiotropic eradication } \\
\text { therapy: }{ }^{13} \mathrm{C} \text { urea breath test, rapid urease test (in OGDS), stool } \\
\text { antigen test }\end{array}$ & A & 1 \\
\hline 4 & $\begin{array}{l}\text { Eradication therapy rendered as aetiological treatment } \\
\text { in } H \text {. pylori positive }\end{array}$ & B & 2 \\
\hline 5 & $\begin{array}{l}\text { Eradication therapy rendered in } H \text {. pylori positive patients } \\
\text { with atrophic gastritis to prevent atrophy advancement }\end{array}$ & A & 1 \\
\hline 6 & $\begin{array}{l}\text { Adequate treatment rendered, including focal endoscopic } \\
\text { resection of visible lower to higher-grade dysplasia or early } \\
\text { cancer foci }\end{array}$ & A & 1 \\
\hline 7 & $\begin{array}{l}\text { H. pylori eradication rendered after endoscopic resection } \\
\text { of adenoma/early gastric cancer to prevent metachronous } \\
\text { tumourisation }\end{array}$ & B & 1 \\
\hline 8 & $\begin{array}{l}\text { Endoscopy rendered once every } 3 \text { years in patients with focal } \\
\text { restricted intestinal metaplasia, provided a familial history } \\
\text { of gastric cancer, incomplete intestinal metaplasia and persistent } \\
H \text {. pylori infection }\end{array}$ & B & 2 \\
\hline 9 & $\begin{array}{l}\text { High-quality endoscopy rendered every } 3 \text { years in patients } \\
\text { with advanced atrophic gastritis (OLGA/OLGIM III/IV severe } \\
\text { atrophy and/or intestinal metaplasia in stomach body and } \\
\text { antrum); endoscopy once in } 1-2 \text { years in patients with advanced } \\
\text { atrophic gastritis and strong familial history of gastric cancer }\end{array}$ & $\mathrm{C}$ & 3 \\
\hline
\end{tabular}

наблюдение при хроническом атрофическом фундальном и мультифокальном гастрите предусматривает прием (осмотр, консультащия) врача-гастроэнтеролога 1 раз в год, прием (осмотр, консультация) врача-онколога по медицинским показаниям с контролируемым показателем стабилизачии морфологических изменений по данным ЭГДС с биопсией. Рекомендуемый интервал наблюдения не разработан в рандомизированных контролируемых исследованиях. Учитывая кроме риска аденокарииномы желудка риск развития нейроэндокринной опухоли желудка, сочетание с другими заболеваниями, ассочиированными с повышенным риском новообразований желудочно-кишечного тракта, а также сроки диспансеризации в соответствии с приказом № 173н, мы рекомендуем эндоскопический контроль 1 раз в 1-2 года.

\section{6. Организация оказания медицинской помощи}

Большинство пациентов с гастритом подлежат наблюдению и лечению в амбулаторных условиях.
Показаниями к плановой госпитализации пациентов с гастритом и дуоденитом служат необходимость проведения дифференциального диагноза при редких формах гастрита (эозинофильный, гранулематозный и др.), выраженная анемия при аутоиммунном гастрите, выраженная клиническая картина заболевания при эрозивном гастрите, необходимость проведения эрадикационной терапии H. pylori под непосредственным врачебным контролем, необходимость выполнения эндоскопической резекции аденомы и раннего рака желудка.

Продолжительность стационарного лечения пациентов с обострением гастрита должна составлять 16 дней.

Показанием к экстренной госпитализации является наличие признаков острого желудочно-кишечного кровотечения у пациента с подозрением на эрозивный гастрит и/или дуоденит.

\section{7. Дополнительная информация \\ (в том числе факторы, влияющие на исход заболевания или состояния)}

Нет. 


\section{Литература / References}

1. Marshall B.J., Warren J.R. Unidentified curved bacilli in the stomach of patients with gastritis and peptic ulceration. Lancet. 1984;1(8390):1311-5. DOI: 10.1016 / s0140-6736(84)91816-6

2. Kusters J.G., van Vliet A.H., Kuipers E.J. Pathogenesis of Helicobacter pylori infection. ClinMicrobiolRev. 2006;19(3):449-90. DOI: 10.1128/CMR.00054-05

3. Graham D.Y., Opekun A.R., Osato M.S., El-Zimaity H.M., Lee C.K., Yamaokaet Y., et al. Challenge model for Helicobacter pylori infection in human volunteers. Gut. 2004;53(9):1235-43. DOI: 10.1136/gut.2003.037499

4. Ansari S., Yamaoka Y. Helicobacter pylori Virulence Factors Exploiting Gastric Colonization and its Pathogenicity. Toxins (Basel). 2019;11(11):677. DOI: 10.3390/ toxins 11110677

5. El-Omar E.M., Carrington M., Chow W.H., McColl K.E., Bream J.H., Young H.A., et al. Interleukin-1 polymorphisms associated with increased risk of gastric cancer. Nature. 2000;404(6776):398-402. DOI: $10.1038 / 35006081$

6. Malfertheiner P., Megraud F., O'Morain C.A., Gisbert J.P., Kuipers E.J., Axon A.T., et al. European Helicobacter and Microbiota Study Group and Consensus panel. Management of Helicobacter pylori infectionthe Maastricht V/Florence Consensus Report. Gut. 2017;66(1):6-30. DOI: 10.1136/gutjnl-2016-312288

7. Sugano K., Tack J., Kuipers E.J., Graham D.Y., ElOmar E.M., Miura S., et al. Kyoto global consensus report on Helicobacter pylorigastritis. Gut. 2015;64:135367. DOI: $10.1136 /$ gutjnl-2015-309252

8. Ивашкин В.Т., Маев И.В., Каприн А.Д., Ага пов М.Ю., Андреев Д.Н., Водолеев А.С. и др. Раннее выявление онкологических заболеваний органов пищеварения (методическое руководство Российской гастроэнтерологической ассоциации и Ассоциации онкологов России для врачей первичного звена здравоохранения). Рос журн гастроэнтерол гепатол колопроктол. 2019;29(5):53-74. [Ivashkin V.T., Mayev I.V., Kaprin A.D., Agapov M.Yu., Andreev D.N., Vodoleev A.S., et al. Early Detection of Oncological Diseases of the Digestive System (Guidelines of the Russian Gastroenterological Association and the Russian Association of Oncologists for Primary Care Physicians). Rus J Gastroenterol Hepatol Coloproctol. 2019;29(5):53-74 (In Russ.)]. DOI: 10.22416/1382-4376-2019-29-5-53-74

9. Симаненков В.И., Маев И.В., Ткачева О.Н, Алексеенко С.А., Андреев Д.Н., Бордин Д.С. и др. Синдром повышенной эпителиальной проницаемости в клинической практике. Мультидисциплинарный национальный консенсус. Кардиоваскулярная терапия и профилактика. 2021;20(1):2758. [Simanenkov V.I., Maev I.V., Tkacheva O.N., Alekseenko S.A., Andreev D.N., Bordin D.S., et al. Syndrome of increased epithelial permeability in clinical practice. Multidisciplinary national Consensus. Cardiovascular Therapy and Prevention. 2021;20(1):2758 (In Russ.)]. DOI: 10.15829/1728-8800-2021-2758

10. Hall S.N., Appelman H.D. Autoimmune Gastritis. Arch Pathol Lab Med. 2019;143(11):1327-31. DOI: 10.5858/ arpa.2019-0345-RA

11. Rodriguez-Castro K.I., Franceschi M., Miraglia C., Russo M., Nouvenne A., Leandro G., et al. Autoimmune diseases in autoimmune atrophic gastritis. Acta Biomed. 2018;89(8-S):100-3. DOI: 10.23750/abm.v89i8-S.7919

12. Лосик Е.А., Селиванова Л.С., Антонова Т.В., Лапина Т.Л., Тертычный А.С., Ивашкин В.T. Морфологические критерии диагноза аутоиммунного гастрита. Российский журнал гастроэнтерологии, гепатологии, колопроктологии. 2016;26(5):13-20. [Losik Y.A., Selivanova L.S., Antonova T.V., Lapina T.L., Tertychny A.S., Ivashkin V.T. Morphological diagnostic criteria of autoimmune gastritis. Rus J Gastroenterol Hepatol Coloproctol. 2016;26(5):13-20 (In Russ.)]. DOI: 10.22416/13824376-2016-26-5-13-20
13. Герман С.В., Зыкова И.Е., Модестова А.В., Ермаков Н.В. Распространенность инфекции Н. pylori среди населения Москвы. Рос журн гастроэнтерол гепатол колопроктол. 2010;20(2):25-30. [German S.V., Zykova I.Ye., Modestova A.V., Yermakov N.V. Prevalence of H. pylori infection in the Moscow population. Rus J Gastroenterol Hepatol Coloproctol. 2010;20(2):25-30 (In Russ.)].

14. Рахманин Ю.А., Зыкова И.Е., Федичкина Т.П., Соленова Л.Г., Герман С.В., Модестова А.В., Кислиuин B.A. Изучение территориального распределения инфицированности Helicobacter pylori трудоспособного населения г. Москвы в ходе диспансеризации производственных контингентов. Гигиена и санитария. 2013;92(5):79-82. [Rakhmanin Yu.A., Zykova I.Ye., Fedichkina T.P., Solenova L.G., German S.V., Modestova A.V., Kislitsin V.A. Regional distribution of Helicobacter pylori infection of able-bodied population of Moscow at medical examination of the production staff. Gigiyena i sanitariya 2013; 92(5):79-82 (In Russ.)].

15. Сварваль А.В., Ферман Р.С., Жебрун А.Б. Изучение динамики превалентности инфекции, обусловленной Helicobacter pylori, среди различных возрастных групп населения Санкт-Петербурга в 2007-2011 годах. Инфекция и иммунитет. 2012;2(4):741-6. [Svarval A.V., Ferman R.S., Zhebrun A.B. Helicobacter pylori prevalence dynamics in different age cohorts of St. Petersburg population in 2007-2011. Infection and Immunity. 2012. 2(4):741-6 (In Russ.)].

16. Решетников О.В., Курилович С.А., Кротов С.А., Кротова В.А. Хеликобактерная инфекция в сибирских популяциях. Бюл. COPАМН. 2010;30(2):88-93. [Reshetnikov O.V., Kurilovich S.A., Krotov S.A., Krotova $V$.A. Helicobacter infection in populations of Siberia. Bull. SB RAMS. 2010; 30(2):88-93 (In Russ.)].

17. Цуканов В.В., Третьякова О.В., Амельчугова О.С., Каспаров Э.В., Родина Д. В., Васютин А.В. и др. Распространенность атрофического гастрита тела желудка у населения г. Красноярска старше 45 лет. Рос журн гастроэнтерол гепатол колопроктол 2012;22(4):27-31. [Tsukanov V.V., Tretyakova O.V., Amelchugova O.S., Kasparov E.V., Rodina D.V., Vasyutin A.V. et al. Prevalence of atrophic corpus gastritis at Krasnoyarsk over 45 year-old population. Rus J Gastroenterol Hepatol Coloproctol. 2012;22(4):27-31 (In Russ.)].

18. Штылашева О.В., Цуканов В.В. Распространенность инфекции Helicobacter pylori и частота диспептических жалоб у населения Хакасии. Рос журн гастроэнтерол гепатол колопроктол. 2004;14(1):33-6. [Shtygasheva O.V., Tsukanov V.V. Prevalence of Helicobacter pylori infection and frequency of dispeptic symptoms in Khakasia population. Rus J Gastroenterol Hepatol Coloproctol. 2004;14(1):33-6 (In Russ.)].

19. Dixon M.F., Genta R.M., Yardley J.H., Correa P. Classification and grading of gastritis. The updated Sydney System. International Workshop on the Histopathology of Gastritis, Houston 1994. Am. J. Surg. Pathol. 1996;20(10):1161-81. DOI: $10.1097 / 00000478$ 199610000-00001

20. Uemura N., Okamoto S., Yamamoto S., Matsumura N., Yamaguchi S., Yamakido M., et al. H. pylori infection and the development of gastric cancer. N Engl J Med. 2001;345:784-9. DOI: 10.1056/NEJMoa001999

21. Meining A., Bayerdörffer E., Müller P., et al. Gastric carcinoma risk index in patients infected with Helicobacter pylori. Virchows Arch. 1998;432(4):311-14. DOI: $10.1007 / \mathrm{s} 004280050171$

22. Miehlke S., Hackelsberger A., Meining A., Hatz R., Lehn N., Malfertheiner P., et al. Severe expression of corpus gastritis is characteristic in gastric cancer patients infected with Helicobacter pylori. $\mathrm{Br} \mathrm{J}$ Cancer. 1998;78(2):263-6. DOI: 10.1038/bjc.1998.475

23. Rugge M., Meggio A., Pennelli G., Piscioli F., Giacomelli L., De Pretis G., et al. Gastritis staging in clinical 
practice: the OLGA staging system. Gut. 2007;56(5):6316. DOI: $10.1136 /$ gut.2006.106666

24. Аруин Л.И., Кононов А.В., Мозговой С.И. Международная классификация хронического гастрита: что следует принять и что вызывает сомнения. Архив патологии. 2009;71(4):11-8. [Aruin L.I., Kononov A.V., Mozgovoy S.I. International classification of chronic gastritis: what to accept or revisit. Pathology Archive. 2009; 71(4):11-18. (In Russ.].

25. Кононов А.В., Потрохова Е.А., Мозговой С.И., Поморгайло Е.Г., Новиков Д.Г. Новая медицинская технология «Молекулярно-генетическая методика прогноза и патоморфологический мониторинг риска развития рака желудка кишечного типа при Helicobacter pyloriинфекции», разрешение Федеральной службы в сфере здравоохранения и социального развития № 2010/220 от 10 июня 2010 г., серия АА 0000001 . [Kononov A.V., Potrokhova E.A., Mozgovoy S.I., Pomorgaylo E.G., Novikov D.G. New medical technique "Molecular genetic prognosis and pathomorphological risk monitoring (In Russ.)].

26. Capelle L.G., de Vries A.C., Haringsma J., Borg F.T., de Vries R.A., Bruno M., et al. The staging of gastritis with the OLGA system by using intestinal metaplasia as an accurate alternative for atrophic gastritis. GastrointestEndosc. 2010;71(7):1150-8. DOI: 10.1016/j.gie.2009.12.029

27. Kimura K., Takemoto T. An endoscopic recognition of the atrophic border and its significance in chronic gastritis. Endoscopy. 1969;1(3):87-97. DOI: $10.1055 / \mathrm{s}-0028$ 1098086

28. Miwata T., Quach D.T., Hiyama T., Aoki R., Le H.M., Tran P.L., et al. Interobserver and intraobserver agreement for gastric mucosa atrophy. BMC Gastroenterol. 2015;15:95. DOI: 10.1186/s12876-015-0327-x

29. Song J.H., Kim S.G., Jin E.H., Lim J.H., Yang S.Y. Risk Factors for Gastric Tumorigenesis in Underlying Gastric Mucosal Atrophy. Gut Liver. 2017;11(5):612-9. DOI: $10.5009 / \mathrm{gnl} 16488$

30. Pimentel-Nunes P., Libânio D., Lage J., Abrantes D., Coimbra M., Esposito G., et al. A multicenter prospective study of the real-time use of narrow-band imaging in the diagnosis of premalignant gastric conditions and lesions. Endoscopy. 2016;48(8):723-30. DOI: $10.1055 / \mathrm{s}-0042$ 108435

31. Кононов А.В., Мозговой С.И., Шиманская А.Г. Прижизненная патолого-анатомическая диагностика болезней органов пищеварительной системы. Клинические рекомендации Российского общества патологоанатомов. М.: Практическая медицина, 2019; 192 . [Kononov A.V., Mozgovoy S.I., Shimanskaya A.G. Life-time morbid anatomy diagnosis of digestive diseases. Clinical recommendations of Russian Society of Pathologists. Moscow: Practical Medicine, 2019; 192 (In Russ.)].

32. Ивашкин В.Т., Маев И.В., Шептулин А.А., Лапи на Т.Л., Трухманов А.С., Картавенко И.М., и др. Клинические рекомендации Российской гастроэнтерологической ассоциации по диагностике и лечению функциональной диспепсии. Рос журн гастроэнтерол гепатол колопроктол. 2017;27(1):50-61. [Ivashkin V.T., Mayev I.V., Sheptulin A.A., Lapina T.L., Trukhmanov A.S., Kartavenko I.M., et al. Diagnosis and treatment of the functional dyspepsia: clinical guidelines of the Russian Gastroenterological Association. Rus J Gastroenterol Hepatol Coloproctol. 2017;27(1):50-61 (In Russ.)]. DOI: $10.22416 / 1382-4376-2017-27-1-50-61$

33. Ивашкин В.Т., Маев И.В., Царьков П.В., Королев М.П., Андреев Д.Н., Баранская Е.К. и др. Диагностика и лечение язвенной болезни у взрослых (Клинические рекомендации Российской гастроэнтерологической ассоциации, Российского общества колоректальных хирургов и Российского эндоскопического общества). Рос журн гастроэнтерол гепатол колопроктол. 2020;30(1):49-70. [Ivashkin V.T., Maev I.V., Tsar'kov P.V., Korolev M.P., Andreev D.N., Baranskaya E.K., et al. Diagnosis and Treatment of Peptic Ulcer in Adults (Clinical Guidelines of the Russian Gastroenterological Association, Russian Society of Colorectal Surgeons and the Russian Endoscopic Society). Rus J Gastroenterol Hepatol Coloproctol. 2020;30(1):49-70 (In Russ.)]. DOI: 10.22416/1382-4376-2020-30-1-49-70

34. Carabotti M., Lahner E., Esposito G., Sacchi M.C., Severi C., Annibale B. Upper gastrointestinal symptoms in autoimmune gastritis: A cross-sectional study. Medicine (Baltimore). 2017; 96(1):e5784. DOI: 10.1097/ MD.0000000000005784

35. Miceli E., Lenti M.V., Padula D., Luinetti O., Vattiato C., Monti C.M., et al. Common features of patients with autoimmune atrophic gastritis. Clin Gastroenterol Hepatol. 2012 Jul;10(7):812-4. DOI: 10.1016/j. cgh.2012.02.018

36. Tenca A., Massironi S., Pugliese D., Consonni D., Mauro A., Cavalcoli F., et al. Gastro-esophageal reflux and antisecretory drugs use among patients with chronic autoimmune atrophic gastritis: a study with $\mathrm{pH}$-impedance monitoring. NeurogastroenterolMotil. 2016;28(2):274-80. DOI: $10.1111 / \mathrm{nmo} .12723$

37. Pruthi H.S., Sharma S.K., Singh B., Anand A.C. Aetiology of upper gastrointestinal haemorrhagean endoscopic study. Med J Armed Forces India. 2000;56(3):188-91. DOI: $10.1016 /$ S0377-1237(17)30162-4

38. Biecker E. Diagnosis and therapy of non-variceal upper gastrointestinal bleeding. World J Gastrointest Pharmacol Ther. 2015;6(4):172-82. DOI: 10.4292/wjgpt.v6.i4.172

39. Лосик Е.А., Ивашкин В.T. Гематологические проявления аутоиммунного гастрита. Рос журн гастроэнтерол гепатол колопроктол. 2016;26(1):37-43. [Losik Ye.A., Ivashkin V.T. Hematological manifestations of autoimmune gastritis. Rus J Gastroenterol Hepatol Coloproctol. 2016;26(1):37-43 (In Russ.)]. DOI: 10.22416/1382-43762016-26-1-37-43

40. Rusak E., Chobot A., Krzywicka A., Wenzlau J. Anti-parietal cell antibodies - diagnostic significance. Adv Med Sci. 2016;61(2):175-9. DOI: 10.1016/j.advms.2015.12.004

41. Lahner E., Norman G.L., Severi C., Encabo S., Shums Z., Vannella L., et al. Reassessment of intrinsic factor and parietal cell autoantibodies in atrophic gastritis with respect to cobalamin deficiency. Am J Gastroenterol. 2009;104(8):2071-9. DOI: 10.1038/ajg.2009.231

42. Huang Y.K., Yu J.C., Kang W.M., Ma Z.-Q., Ye X., Tian S.-B., et al. Significance of serum pepsinogens as a biomarker for gastric cancer and atrophic gastritis screening: a systematic review and meta-analysis. PLoS One. 2015;10(11):e0142080. DOI: 10.1371/journal. pone. 0142080

43. Zagari R.M., Rabitti S., Greenwood D.C., Eusebi L.H., Vestito A., Bazzoli F. Systematic review with meta-analysis: diagnostic performance of the combination of pepsinogen, gastrin-17 and anti-Helicobacter pylori antibodies serum as- says for the diagnosis of atrophic gastritis. Aliment Pharmacol Ther. 2017;46(7):657-67. DOI: 10.1111/ apt. 14248

44. Watabe H., Mitsushima T., Yamaji Y., Okamoto M., Wada R., Kokubo T., et al. Predicting the development of gastric cancer from combining Helicobacter pylori antibodies and serum pepsinogen status: a prospective endoscopic cohort study. Gut. 2005;54(6):764-8. DOI: 10.1136/gut.2004.055400

45. Kurilovich S., Belkovets A., Reshetnikov O., Openko T., Malyutina S., Ragino Y., et al. Stomach-specific Biomarkers (GastroPanel) Can Predict the Development of Gastric Cancer in a Caucasian Population: A Longitudinal Nested Case-Control Study in Siberia. Anticancer Res. 2016;36(1):247-53. PMID: 26722050

46. Pimentel-Nunes P., Libânio D., Marcos-Pinto R., Areia M., Leja M., Esposito G., et al. Management of epithelial precancerous conditions and lesions in the stomach (MAPS II): European Society of Gastrointestinal Endoscopy (ESGE), European Helicobacter and Microbiota Study Group (EHMSG), European Society of Pathology (ESP), 
and Sociedade Portuguesa de Endoscopia Digestiva (SPED) guideline update 2019. Endoscopy. 2019;51(4):365-88. DOI: $10.1055 / \mathrm{a}-0859-1883$

47. Banks M., Graham D., Jansen M., Gotoda T., Coda S., di Pietro M., et al. British Society of Gastroenterology guidelines on the diagnosis and management of patients at risk of gastric adenocarcinoma. Gut. 2019;68(9):1545-75. DOI: $10.1136 /$ gutjnl-2018-318126

48. Zhao Z., Yin Z., Wang S., Wang J., Bai B., Qiu Z., et al. Meta-analysis: The diagnostic efficacy of chromoendoscopy for early gastric cancer and premalignant gastric lesions. J Gastroenterol Hepatol. 2016;31(9):1539-45. DOI: $10.1111 /$ jgh.13313

49. Ang T.L., Pittayanon R., Lau J.Y., Rerknimitr R., Ho S.H., Singh R., et al. A multicenter randomized comparison between high-definition white light endoscopy and narrow band imaging for detection of gastric lesions. Eur J Gastroenterol Hepatol. 2015;27(12):1473-8. DOI: 10.1097/MEG.0000000000000478

50. Kikuste I., Marques-Pereira R., Monteiro-Soares M., Pimentel-Nunes P., Areia M., Leja M., et al. Systematic review of the diagnosis of gastric premalignant conditions and neoplasia with high-resolution endoscopic technologies. Scand J Gastroenterol. 2013;48(10):1108-17. DOI: 10.3109/00365521.2013.825315

51. Pimentel-Nunes P., Dinis-Ribeiro M., Soares J.B., Mar cos-Pinto R., Santos C., Rolandaet C., et al. A multicenter validation of an endoscopic classification with narrow band imaging for gastric precancerous and cancerous lesions. Endoscopy. 2012;44(3):236-46. DOI: $10.1055 / \mathrm{s}-$ 0031-1291537

52. East J.E., Vleugels J.L., Roelandt P., Bhandari P., Biss chops R., Dekker E., et al. Advanced endoscopic imaging: European Society of Gastrointestinal Endoscopy (ESGE) Technology Review. Endoscopy. 2016;48(11):1029-45. DOI: $10.1055 / \mathrm{s}-0042-118087$

53. Rugge M., Genta R.M., Fassan M., Valentini E., Coati I., Guzzinati S., et al. OLGA Gastritis Staging for the Prediction of Gastric Cancer Risk: A Long-term Follow-up Study of 7436 Patients. Am J Gastroenterol. 2018;113(11):1621-8. DOI: 10.1038/s41395-018-0353-8

54. Mao X.Y., Xu S.F., Liu Q., Jiang J.X., Zhang H.H., Sang H.M., et al. Anatomical predilection of intestinal metaplasia based on 78,335 endoscopic cases. Saudi J Gastroenterol. 2016;22(2):154-60. DOI: 10.4103/13193767.178528

55. Kim Y.I., Kook M.C., Cho S.J., Lee J.Y., Kim C.G., Joo J., et al. Effect of biopsy site on detection of gastric cancer high-risk groups by OLGA and OLGIM stages. Helicobacter. 2017;22(6). DOI: 10.1111/hel.12442

56. Isajers S., Liepniece-Karele I., Janciauskas D., Moisejevs G., Funka K., Kikuste I., et al. The effect of incisura angularis biopsy sampling on the assessment of gastritis stage. Eur J Gastroenterol Hepatol. 2014;26(5):510-3. DOI: $10.1097 /$ MEG.0000000000000082

57. Varbanova M., Wex T., Jechorek D., Röhl F.W., Langner C., Selgradet M., et al. Impact of the angulus biopsy for the detection of gastric preneoplastic conditions and gastric cancer risk assessment. J Clin Pathol. 2016;69(1):19-25. DOI: 10.1136/jclinpath-2015-202858

58. Lan H.C., Chen T.S., Li A.F., Chang F.Y., Lin H.C. Additional corpus biopsy enhances the detection of Helicobacter pylori infection in a background of gastritis with atrophy. BMC Gastroenterol. 2012;12:182. DOI: 10.1186/1471-230X-12-182

59. Shin C.M., Kim N., Lee H.S., Lee H.E., Lee S.H., Park Y.S., et al. Validation of diagnostic tests for Helicobacter pylori with regard to grade of atrophic gastritis and or intestinal metaplasia. Helicobacter. 2009;14(6):512-9. DOI: $10.1111 /$ j.1523-5378.2009.00726.x

60. Best L.M., Takwoingi Y., Siddique S., Selladurai A., Gandhi A., Low B., et al. Non-invasive diagnostic tests for Helicobacter pylori infection. Cochrane Database Syst Rev. 2018;3(3):CD012080. DOI: 10.1002/14651858. CD012080.pub2
61. Abd Rahim M.A., Johani F.H., Shah S.A., Hassan M.R., Abdul Manaf M.R. ${ }^{13} \mathrm{C}$-Urea Breath Test Accuracy for Helicobacter pylori Infection in the Asian Population: A Meta-Analysis. Ann Glob Health. 2019;85(1):110. DOI: $10.5334 / \operatorname{aogh} .2570$

62. Mansori K., Dehghanbanadaki H., Naderpour S., Rashti R., Moghaddam A.B., Moradi Y. A systematic review and meta-analysis of the prevalence of Helicobacter pylori in patients with diabetes. Diabetes Metab Syndr. 2020;14(4):601-7. DOI: 10.1016/j.dsx.2020.05.009

63. Dechant F.X., Dechant R., Kandulski A., Selgrad M., Weber F., Reischl U., et al. Accuracy of Different Rapid Urease Tests in Comparison with Histopathology in Patients with Endoscopic Signs of Gastritis. Digestion. 2020;101(2):184-90. DOI: 10.1159/000497810

64. Yakoob J., Jafri W., Abid S., Jafri N., Abbas Z., Hamid S., et al. Role of rapid urease test and histopathology in the diagnosis of Helicobacter pylori infection in a developing country. BMC Gastroenterol. 2005;5:38. DOI: 10.1186/1471-230X-5-38

65. Hsu W.H., Wang S.S., Kuo C.H., Chen C.Y., Chang C.W., Hu H.M., et al. Dual specimens increase the diagnostic accuracy and reduce the reaction duration of rapid urease test. World J Gastroenterol. 2010;16(23):2926-30. DOI: 10.3748/wjg.v16.i23.2926

66. Ивашкин B.T., Маев И.В., Лапина Т.Л., Шептулин А.А., Трухманов А.С., Баранская Е.К. и лр. Клинические рекомендации Российской гастроэнтерологической ассоциации по диагностике и лечению инфекции Helicobacter pylori у взрослых. Рос журн гастроэнтерол гепатол колопроктол. 2018;28(1):55-70. [Ivashkin V.T., Mayev I.V., Lapina T.L., Sheptulin A.A., Trukhmanov A.S., Baranskaya Y.K., et al. Diagnostics and treatment of Helicobacter pylori infection in adults: Clinical guidelines of the Russian gastroenterological association. Rus J Gastroenterol Hepatol Coloproctol. 2018;28(1):5570 (In Russ.)]. DOI: 10.22416/1382-4376-2018-28-1-55-70

67. Ливзан М.А., Кононов А.В., Мозговой С.И. Течение хронического гастрита, ассоциированного с Helicobacter pylori, 8 постэрадикационном периоде. Экспериментальная и клиническая фармакология. 2007;5:116-23. [Livzan M.A., Kononov A.V., Mozgovoy S.I. Sequence of Helicobacter pylori-associated chronic gastritis in post-eradication period. Experimental and Clinical Pharmacology. 2007; 5:116-123. (In Russ.)].

68. Кононов А.В., Мозговой С.И., Ливзан М.А. и др. Морфология поверхностного и атрофического хронического гастрита при эрадикации Helicobacter pylori. Архив патологии. 2005;3:17-21. [Kononov A.V., Mozgovoy S.I., Livzan M.A. et al. Morphology of superficial and atrophic chronic gastritis during Helicobacter pylori eradication. Pathology Archive. 2005; 3:17-21.(In Russ.)].

69. Kyzekova J., Mour J. The effect of eradication therapy on histological changes in the gastric mucosa in patients with non-ulcer dyspepsia and Helicobacter pylori infection. Prospective randomized intervention study. Hepatogastroenterology. 1999;46(27):2048-56.

70. Abdul Rasheed Z., Gautam S., Ukabam S., Nayal S. Resolution of gastritis induced by Helicobacter pylori 4-5 weeks after successful eradication of infection using a triple therapy regimen of pantoprazole, amoxycillin and clarithromycin for one week. Digestion. 1999;60(3):286-97. DOI: $10.1159 / 000007673$

71. Genta R.M., Lew G.M., Graham D.Y. Changes in gastric mucosa following eradication of Helicobacter pylori. Mod Pathol. 1993;6(3):281-9.

72. Rugge, M., Sugano, K., Sacchi, D., et al. Gastritis: An Update in 2020. Curr Treat Options Gastro. 2020;18:488503. DOI: $10.1007 / \mathrm{s} 11938-020-00298-8$

73. Wang J., Xu L., Shi R., Huang X., Li S.W.H., Huang Z., et al. Gastric atrophy and intestinal metaplasia before and after Helicobacter pylori eradication: a meta-analysis. $\mathrm{Di}^{-}$ gestion. 2011;83(4):253-60. DOI: 10.1159/000280318

74. Rokkas T., Pistolias D., Sechopoulos P., Robotis I., Margantinis $G$. The long-term impact of Helicobacter 
pylori eradication on gastric histology: a systematic review and meta-analysis. Helicobacter. 2007;12:32-8. DOI: 10.1111/j.1523-5378.2007.00563.x

75. Kong Y.J., Yi H.G., Dai J.C., Wei M.-X. Histological changes of gastric mucosa after Helicobacter pylori eradication: a systematic review and meta-analysis. World J Gastroenterol. 2014;20(19):5903-11. DOI: 10.3748/wjg. v20.i19.5903

76. McColl K., Murray L., El-Omar E., Dickson A., ElNujumi A., Wirz A., et al. Symptomatic benefit from eradicating Helicobacter pylori infection in patients with nonulcer dyspepsia. N Engl J Med. 1998;339(26):1869-74. DOI: $10.1056 /$ NEJM199812243392601

77. Madisch A., Miehlke S., Neuber F., Morgner A., Kuhlisch E., Rappel S., et al. Healing of lymphocytic gastritis after Helicobacter pylori eradication therapy - a randomized, double-blind, placebo-controlled multicentre trial. Aliment Pharmacol Ther. 2006; 23(4):473-9. DOI: 10.1111/j.1365-2036.2006.02778.x

78. Lee V.W., Chau T.S., Chan A.K., Lee K.K., Waye M.M., Ling T.K., et al. Pharmacogenetics of esomeprazole or rabeprazole-based triple therapy in Helicobacter pylori eradication in Hong Kong non-ulcer dyspepsia Chinese subjects. J Clin Pharm Ther. 2010;35(3):343-50. DOI: 10.1111/j.1365-2710.2009.01088.x

79. Liang X., Xu X., Zheng Q., Zhang W., Sun Q., Liu W., et al. Efficacy of bismuth-containing quadruple therapies for clarithromycin-, metronidazole-, and fluoroquinoloneresistant Helicobacter pylori infections in a prospective study. Clin Gastroenterol Hepatol. 2013;11(7):802-7. DOI: $10.1016 / \mathrm{j} . \operatorname{cgh} .2013 .01 .008$

80. Soh J.S., Kang H.S., Yang Y.J., Hong J.T., Shin S.P., Suk K.T., et al. Amoxicillin or tetracycline in bismuth-containing quadruple therapy as first-line treatment for Helicobacter pylori infection. Gut Microbes. 2020;11(5):131423. DOI: $10.1080 / 19490976.2020 .1754118$

81. Chang Y.L., Tung Y.C., Tu Y.K., Yeh H.Z., Yang J.C., Hsu P.I., et al. Efficacy of second-line regimens for Helicobacter pylori eradication treatment: a systemic review and network meta-analysis. BMJ Open Gastroenterol. 2020;7(1):e000472. DOI: 10.1136/bmjgast-2020-000472

82. Gisbert J.P., Castro-Fernández M., Bermejo F., PérezAisa A., Ducons J., Fernández-Bermejo M., et al. Thirdline rescue therapy with levofloxacin after two H. pylori treatment failures. Am J Gastroenterol. 2006;101(2):2437. DOI: $10.1111 / \mathrm{j} .1572-0241.2006 .00457 . x$

83. Marzio L., Coraggio D., Capodicasa S., Grossi L., Cappello $G$. Role of the preliminary susceptibility testing for initial and after failed therapy of Helicobacter pylori infection with levofloxacin, amoxicillin, and esomeprazole. Helicobacter. 2006;11(4):237-42. DOI: 10.1111/j.1523 5378.2006.00407.x

84. Yuan Y., Ford A.C., Khan K.J., Gisbert J.P., Forman D., Leontiadis G.I., et al. Optimum duration of regimens for Helicobacter pylori eradication. Cochrane Database Syst Rev. 2013;12:CD008337. DOI: 10.1002/14651858. CD008337.pub2

85. Gisbert J.P., McNicholl A.G. Optimization strategies aimed to increase the efficacy of H.pylori eradication therapies. Helicobacter. 2017;22(4). DOI: 10.1111/hel.12392

86. Villoria A., Garcia P., Calvet X., Gisbert J.P., Vergara $M$. Meta-analysis: high-dose proton pump inhibitors vs. standard dose in triple therapy for Helicobacter pylori eradication. Aliment Pharmacol Ther. 2008; 28(7):868-77. DOI: $10.1111 / \mathrm{j} .1365-2036.2008 .03807 . \mathrm{x}$

87. Vallve M., Vergara M., Gisbert J.P., Calvet X. Single vs. double dose of a proton pump inhibitor in triple therapy for Helicobacter pylori eradication: a meta-analysis. Aliment Pharmacol Ther. 2002;16(6):1149-56. DOI: 10.1046/j.1365-2036.2002.01270.x

88. McNicholl A.G., Linares P. M., Nyssen O.P., Gisbert J.P. Meta-analysis: esomeprazole or rabeprazole vs. first-generation pump inhibitors in the treatment of Helicobacter pylori infection. Aliment Pharmacol Ther. 2012;36(5):41425. DOI: $10.1111 /$ j.1365-2036.2012.05211.x
89. Ko S.W., Kim Y.-J., Chung W.C., Lee S.J. Bismuth supplements as the firstline regimen for Helicobacter pylori eradication therapy: Systemic review and metaanalysis. Helicobacter. 2019; 24(2):e12565. DOI: 10.1111/hel.12565 90. Dore M.P., Lu H., Graham D.Y. Role of bismuth in improving Helicobacter pylori eradication with triple therapy. Gut. 2016;65(5):870-8. DOI: 10.1136 / gutjnl-2015-311019

91. Dang Y., Reinhardt J.D., Zhou X., Zhang G. The effect of probiotics supplementation on Helicobacter pylori eradication rates and side effects during eradication therapy: a meta-analysis. PLoS One. 2014; 9(11):e111030. DOI: 10.1371/journal.pone.0111030

92. McFarland L.V., Huang Y., Wang L., Malfertheiner P. Systematic review and meta-analysis: Multi-strain probiotics as adjunct therapy for Helicobacter pylori eradication and prevention of adverse events. United European Gastroenterology Journal. 2016;4(4):546-61. DOI: $10.1177 / 2050640615617358$

93. Lv Z., Wang B., Zhou X., Wang F., Xie Y., Zheng H., et al. Efficacy and safety of probiotics as adjuvant agents for Helicobacter pylori infection: a meta-analysis. Exp Ther Med. 2015;9(3):707-16. DOI: 10.3892/etm.2015.2174

94. Zhang M.-M., Qian W., Qin Y.-Y., He J., Zhou Y.-H. Probiotics in Helicobacter pylori eradication therapy: a systematic review and meta-analysis. World J Gastroenterol. 2015;21(14):4345-57. DOI: 10.3748/wjg.v21.i14.4345

95. Nishizawa T., Nishizawa Y., Yahagi N., Kanai T. Takahashi M., Suzuki H. Effect of supplementation with rebamipide for Helicobacter pylori eradication therapy: a systematic review and meta-analysis. J Gastroenterol Hepatol. 2014;29(4):20-4. DOI: 10.1111/jgh.12769

96. Du Y., Bai Y., Xie P., Fang J., Wang X., Hou X., et al. Chronic gastritis in China: a national multi-center survey. BMC Gastroenterol. 2014;14:21. DOI: 10.1186/1471230X-14-21

97. Hawkey C.J., Wilson I., Naesdal J., Långström G., Swannell A.J., Yeomans N.D. Influence of sex and Helicobacter pylori on development and healing of gastroduodenal lesions in non-steroidal anti-inflammatory drug users. Gut. 2002;51(3):344-50. DOI: 10.1136/gut.51.3.344

98. Ng F.H., Wong S.Y., Lam K.F., Chu W.M., Chan P., Ling Y.H., et al. Famotidine is inferior to pantoprazole in preventing recurrence of aspirin-related peptic ulcers or erosions. Gastroenterology. 2010;138(1):82-88. DOI: 10.1053/j.gastro.2009.09.063

99. Wilson I., Långström G., Wahlqvist P., Walan A., Wiklund I., Naesdal J. Management of gastroduodenal ulcers and gastrointestinal symptoms associated with nonsteroidal anti-inflammatory drug therapy: A summary of four comparative trials with omeprazole, ranitidine, misoprostol, and placebo. Current therapeutic research. 2001;62(12):835-50.

100.Каратеев А.Е., Насонов Е.Л., Ивашкин В.Т. Мартьнов А.И., Яхно Н.Н., Арутюнов Г.П. и др. Рациональное использование нестероидных противовоспалительных препаратов. Клинические рекомендации. Научно-практическая ревматология. 2018;56:1-29. [Karateev A.E., Nasonov E.L., Ivashkin V.T., Martynov A.I., Yakhno N.N., Arutyunov G.P., et al. Rational use of nonsteroidal anti-inflammatory drugs. Clinical guidelines. Rheumatology Science and Practice. 2018;56:1-29 (In Russ.)]. DOI: $10.14412 / 1995-4484-2018-1-29$

101.Du Y., Li Z., Zhan X., Chen J., Gao J., Gong Y., et al. Anti-inflammatory effects of rebamipide according to Helicobacter pylori status in patients with chronic erosive gastritis: a randomized sucralfate-controlled multicenter trial in China-STARS study. DigDisSci. 2008;53(11):2886-95. DOI: $10.1007 / \mathrm{s} 10620-007-0180-\mathrm{z}$

102.Kim G.H., Lee H.L., Joo M.K., Park H.J., Jung S.W., Lee O.J., et al. Efficacy and Safety of Rebamipide versus Its New Formulation, AD-203, in Patients with Erosive Gastritis: A Randomized, Double- Blind, Active Control, Noninferiority, Multicenter, Phase 3 Study. Gut Liver. 2021. DOI: $10.5009 / \mathrm{gnl} 20338$ 
103.Kumar S., Dewan B., Shah D. A Comparative Evaluation of Lafutidine and Rabeprazole in the Treatment of Gastritis and Peptic Ulcer: A Double-blind, Randomized Study in Indian Patients. Journal of Advances in Medicine and Medical Research. 2013;3(4):1187-98. DOI: 10.9734/ $\mathrm{BJMMR} / 2013 / 3173$

104.Кононов А.В., Мозговой С.И., Рыбкина Л.Б., Бунова С.С., Шиманская А.Г. Оценка цитопротективного влияния висмута трикалия дицитрата на слизистую оболочку желудка при эрадикации Н. pylori и пролонгированном приеме препарата. Рос журн гастроэнтерол гепатол колопроктол. 2006;16(6):21-8. [Kononov A.V., Mozgovoy S.I., Rybkina L.B., Bunova S.S., Shimanskaya A.G. Assessment of bismuth tripotassium dicitrate cytoprotective effect on stomach mucosa at $\mathrm{H}$. pylori eradication and prolonged drug administration. Rus J Gastroenterol Hepatol Coloproctol. 2006;16(6):21-8 (In Russ.)].

105.Лапина Т.Л. Возможности лекарственного воздействия на цитопротективные свойства гастродуоденальной слизистой оболочки. Рос жур гастроэнтерол гепатол колопроктол. 2006;16(5):2-7. [Lapina T.L. Pharmaceutical options of modulation gastroduodenal mucosa cytoprotection. Rus J Gastroenterol Hepatol Coloproctol. 2006;16(5):2-7 (In Russ.)].

106. Han X., Jiang K., Wang B., Zhou L., Chen X., Li S. Effect of rebamipide on the premalignant progression of chronic gastritis: a randomized controlled study. Clin Drug Investig. 2015;35(10):665-73. DOI: 10.1007 /s40261-015$0329-\mathrm{z}$

107.Kamada T., Sato M., Tokutomi T., Watanabe T., Murao T., Matsumoto H., et al. Rebamipide improves chronic inflammation in the lesser curvature of the corpus after Helicobacter pylori eradication: a multicenter study. Biomed Res Int. 2015;2015:865146 - 86514. DOI: $10.1155 / 2015 / 865146$

108.Simadibrata, M., Syam, A., Rani, A., Wanandi, S., Fauzi, A., Abdullah, M. Anti free radical \& anti inflammatory effect of rebamipide in chronic gastritis. Open Journal of Gastroenterology. 2013;3:72-7. DOI: 10.4236 / ojgas.2013.31011

109.Seo G.H., Lee H. Chemopreventive Effect of Rebamipide against Gastric Cancer in Patients who undergo Endoscopic Resection for Early Gastric Neoplasms: A Nationwide Claims Study. Digestion. 2019;100(4):221-8. DOI: 10.1159/000495288

110. Naito Y., Yoshikawa T. Rebamipide: a gastrointestinal protective drug with pleiotropic activities. Expert Rev Gastroenterol Hepatol. 2010;4(3):261-70. DOI: 10.1586/ egh.10.25

111. Haruma K., Ito $M$. Review article: clinical significance of mucosal- protective agents: acid, inflammation, carcinogenesis and rebamipide. Aliment PharmacolTher. 2003;18(1):153-9. DOI: 10.1046/j.1365-2036.18.s1.17.x

112.Pinto-Sanchez M.I., Yuan Y., Hassan A., Bercik P., Moayyedi $P$. Proton pump inhibitors for functional dyspepsia. Cochrane Database Syst Rev. 2017;11(11):CD011194. DOI: 10.1002/14651858.CD011194.pub3

113. Moayyedi P., Delaney B.C., Vakil N., Forman D., Talley N.J. The efficacy of proton pump inhibitors in nonulcer dyspepsia: a systematic review and economic analysis. Gastroenterology. 2004;127(5):1329-37. DOI: 10.1053/j. gastro.2004.08.026

114.Oh J.H., Kwon J.G., Jung H.K., Tae C.H., Song K.H., Kang S.J., et al. Clinical Practice Guidelines for Functional Dyspepsia in Korea. J NeurogastroenterolMotil. 2020;26(1):29-50. DOI: 10.5056/jnm19209

115.Stanghellini V., Chan F.K.L., Hasler W.L., Malagelada J.R., Suzuki H., Tack J., et al. Gastroduodenal Disorders. Gastroenterology. 2016;150(6):1380-92. DOI: 10.1053/j.gastro.2016.02.011

116. Yang Y.J., Bang C.S., Baik G.H., Park T.Y., Shin S.P., Suk K.T., et al. Prokinetics for the treatment of func tional dyspepsia: Bayesian network meta-analysis. BMC Gastroenterol. 2017;17(1):83. DOI: 10.1186/s12876-0170639-0
117.Huang X., Lv B., Zhang S., Fan Y.H., Meng L.N. Itopride therapy for functional dyspepsia: a meta-analysis. World J Gastroenterol. 2012;18(48):7371-7. DOI: 10.3748/wjg.v18.i48.7371

118. Veldhuyzen van Zanten S.J., Jones M.J., Verlinden M., Talley N.J. Efficacy of cisapride and domperidone in functional (nonulcer) dyspepsia: a meta-analysis. Am J Gastroenterol. 2001;96(3):689-96. DOI: 10.1111/j.1572$0241.2001 .03521 . \mathrm{x}$

119.Zhong Y.Q., Zhu J., Guo J.N., Yan R., Li H.J., Lin Y.H., et al. A randomized and case-control clinical study on trimebutine maleate in treating functional dyspepsia coexisting with diarrhea-dominant irritable bowel syndrome. ZhonghuaNeiKe Za Zhi. 2007;46(11):899-902

120.Kountouras J., Gavalas E., Papaefthymiou A., Tsechelidis I., Polyzos S.A., Bor S., et al. Trimebutine Maleate Monotherapy for Functional Dyspepsia: A Multicenter, Randomized, Double-Blind Placebo Controlled Prospective Trial. Medicina (Kaunas). 2020;56(7):339. DOI: $10.3390 /$ medicina56070339

121.Кардашева С.С., Картавенко И.М., Максимова Н.Б., Юрвева Е.Ю., Попова И.Р., Павлов Ч.С., Ивашкин B.T. Эффективность тримебутина малеата в лечении пациентов с функциональной диспепсией: результаты наблюдательного исследования «TREND». Рос журн гастроэнтерол гепатол колопроктол. 2018;28(5):67-76. [Kardasheva S.S., Kartavenko I.M., Maksimova N.B., Yurieva E.Yu., Popova I.R., Pavlov Ch.S., Ivashkin V.T. Efficacy of Trimebutine Maleate (Trimedat ${ }^{\circledR}$ ) in the Treatment of Patients with Functional Dyspepsia: Results of the "TREND" Observational Study. Rus J Gastroenterol Hepatol Coloproctol. 2018;28(5):67-76 (In Russ.)]. DOI: $10.22416 / 1382-4376-2018-28-5-67-76$

122.Андреев Д.Н., Маев И.В. Эффективность тримебутина в рамках лечения функциональных заболеваний желудочно-кишечного тракта и желчных путей: наблюдательное многоцентровое исследование. Терапевтический архив. 2021;93(8):897-903. [Andreev D.N., Maev I.V. Efficacy of trimebutine in the treatment of functional gastrointestinal disorders: an observational multicenter study. Terapevticheskii arkhiv. 2021;93(8):897-903 (In Russ.)]. DOI: $10.26442 / 00403660.2021 .08 .200919$

123.Poynard T., Regimbeau C., Benhamou Y. Meta-analysis of smooth muscle relaxants in the treatment of irritable bowel syndrome. Aliment Pharmacol Ther. 2001;15(3):355-61. DOI: $10.1046 /$ j.1365-2036.2001.00937.x

124.Holtmann G., Talley N. J., Liebregts T., Adam B., Parow C. A placebo-controlled trial of itopride in functional dyspepsia. N Engl J Med. 2006;354(8):832-40. DOI: $10.1056 /$ NEJMoa052639

125.Ивашкин B.T., Шептулин А.А., Трухманов А.С. Эффективность применения ганатона (итоприда гидрохлорида) в лечении больных функциональной диспепсией. Фарматека. 2009;13:50-4.[ Ivashkin V.T., Sheptulin A.A., Trukhmanov A.S. Efficacy of ganaton (itopride hydrochloride) in treatment for functional dyspepsia. Farmateka. 2009; 13:50-4. (In Russ.)].

126. Sawant P., Das H.S., Desai N., Kalokhe S., Patil S. Comparative evaluation of the efficacy and tolerability of itopride hydrochloride and domperidone in patients with non-ulcer dyspepsia. J Assoc Physicians India. $2004 ; 52: 626-8$.

127.Лазебник Л.Б., Алексеенко С.А., Лялюкова Е.А. и др. Рекомендации по ведению первичных пациентов с симптомами диспепсии. Экспериментальная и клиническая гастроэнтерология. 2018; 5:4-18.[ Lazebnik L.B., Alekseenko S.A., Lyalyukova E.A. et al. Guidelines on primary patient management in dyspepsia. Experimental and Clinical Gastroenterology. 2018;(5):4-18. (In Russ.)].

128.Jaafar M.H., Safi S.Z., Tan M.P., Rampal S., Mahadeva $S$. Efficacy of Rebamipide in Organic and Functional Dyspepsia: A Systematic Review and Meta-Analysis. Dig Dis Sci. 2018;63(5):1250-60. DOI: $10.1007 / \mathrm{s} 10620-017-$ 4871-9 
129.Zhao G., Xue M., Hu Y., Lai S., Chen S., Wang L. How commonly is the diagnosis of gastric low grade dysplasia upgraded following endoscopic resection? A meta-analysis. PLoSOne 2015;10(7):e0132699. DOI: 10.1371/journal. pone.0132699

130.Sung J.K. Diagnosis and management of gastric dysplasia. Korean J InternMed. 2016;31(2):201-9. DOI: 10.3904/ kjim.2016.021

131. Correa $P$. Clinical implications of recent developments in gastric can- cer pathology and epidemiology. Semin Oncol. $1985 ; 12: 2-10$.

132. Lauwers G., Carneiro F., Graham D., et al. Gastric carcinoma. In: Theise N, ed. WHO Classification of tumours of the digestive system. Lyon: IARC Press. 2010;48-58.

133.Лейзерман В.Г., Бугрова О.В., Красикова С.И. Восстановительная медицина. М.: Феникс, 2008. [Leyzerman V.G., Bugrova O.V., Krasikova S.I. Restorative medicine. Feniks. 2008 (In russ.)].

134.Lee Y.C., Chiang T.H., Chou C.K., Tu Y.-K., Liao W.-C., Wu M.-S., et al. Association between Helicobacter pylori eradication and gastric cancer incidence: a systematic review and meta-analysis. Gastroenterology. 2016;150(5):1113-24.e5. DOI: 10.1053/j.gastro.2016.01.028

135.Ford A.C., Yuan Y., Moayyedi P. Helicobacter pylori eradication therapy to prevent gastric cancer: systematic review and meta-analysis. Gut. 2020; 69(12):2113-2121. DOI: $10.1136 /$ gutjnl-2020-320839

136.Chiang T.H., Chang W.J., Chen S.L., Yen A.M., Fann J.C., Chiu S.Y., et al. Mass eradication of Helicobacter pylori to reduce gastric cancer incidence and mortality: a long-term cohort study on Matsu Islands. Gut. 2021;70(2):243-50. DOI: 10.1136/gutjnl-2020-322200.

137.Ma J.L., Zhang L., Brown L.M., Shen L., Pan K.-F., Liu W.-D. et al. Fifteen-year effects of Helicobacter pylori, garlic, and vitamin treatments on gastric cancer incidence and mortality. J Natl Cancer Inst. 2012;104(6):48892. DOI: $10.1093 /$ jnci/djs003

138. Wong B.C.-Y, Lam S.K., Wong W.M., Chen J.S., Zheng T.T., Feng R.E., et al. Helicobacter pylori eradication to prevent gastric cancer in a high-risk region of China: a randomized controlled trial. JAMA. 2004;291(2):187-94. DOI: $10.1001 /$ jama.291.2.187

139. Choi I.J., Kook M.C., Kim Y.I., Cho S.-J., Lee J.Y., Kim C.G., et al. Helicobacter pylori therapy for the prevention of metachronous gastric cancer. $\mathrm{N}$ Engl J Med. 2018;378(12):1085-95. DOI: 10.1056/NEJMoa1708423

140.Bang C.S., Baik G.H., Shin I.S., Kim J.B., Suk K.T., Yoon J.H., et al. Helicobacter pylori eradication for prevention of metachronous recurrence after endoscopic resection of early gastric cancer. J Korean Med Sci. 2015;30(6):749-56.

141.Jung D.H., Kim J.H., Chung H.S., Park J.C., Shin S.K., Lee S.K., et al. Helicobacter pylori eradication on the prevention of metachronous lesions after endoscopic resection of gastric neoplasm: a meta-analysis. PLoSOne. 2015;10(4):e0124725. DOI: 10.1371/journal.pone.0124725

142.Ивашкин В.Т., Лапина Т.Л., Шептулин А.А., Трухма нов А.С., Маев И.В., Драпкина О.М. и др. Практические шаги по профилактике рака желудка в Российской Федерации: алгоритм ведения пациентов с хроническим геликобактерным гастритом (Материалы и резолюция совета экспертов 9 декабря 2013 г.). Рос журн гастроэнтерол гепатол колопроктол. 2014;24(2):102-4. [Ivashkin V.T., Lapina T.L., Sheptulin A.A., Trukhmanov A.S., Maev I.V., Drapkina O.M., et al. Practical steps on stomach cancer prevention in the Russian Federation: H. pyloriassociated gastritis management algorithm (Advisory board position statement, December, 9, 2013). Rus J Gastroenterol Hepatol Coloproctol. 2014;24(2):102-4 (In Russ.)].
143.Song H., Ekheden I.G., Zheng Z., et al. Incidence of gastric cancer among patients with gastric precancerous lesions: observational cohort study in a low risk Western population. BMJ. 2015; 351: h3867. DOI: $10.1136 / \mathrm{bmj}$. h4134

144.Rugge M., Meggio A., Pravadelli C., Barbareschi M., Fassan M., Gentilini M., et al. Gastritis staging in the endoscopic follow-up for the secondary prevention of gastric cancer: a 5-year prospective study of 1755 patients. Gut. 2019;68(1):11-7. DOI: 10.1136/gutjnl-2017-314600

145. Cho S.J., Choi I.J, Kook M.C., Nam B.-H., Kim C.G., Lee J.Y., et al. Staging of intestinal- and diffuse-type gastric cancers with the OLGA and OLGIM staging systems. Aliment Pharmacol Ther. 2013;38(10):1292-302. DOI: $10.1111 /$ apt. 12515

146. Kodama M., Murakami K., Okimoto T., Abe H., Sato R., Ogawa R., et al. Histological characteristics of gastric mucosa prior to Helicobacter pylori eradication may predict gastric cancer. Scand J Gastroenterol. 2013;48(11):124956. DOI: $10.3109 / 00365521.2013 .838994$

147.Mera R.M., Bravo L.E., Camargo M.C., Bravo J.C., Delgado A.G., Romero-Gallo J., et al. Dynamics of Helicobacter pylori infection as a determinant of progression of gastric precancerous lesions: 16-year follow-up of an eradication trial. Gut. 2018;67(7):1239-46. DOI: 10.1136/ gutjnl-2016-311685

148.Gonzalez C.A., Sanz-Anquela J.M., Companioni O., Bonet C., Berdasco M., López C., et al. Incomplete type of intestinal metaplasia has the highest risk to progress to gastric cancer: results of the Spanish follow-up multicenter study. J Gastroenterol Hepatol. 2016;31(5):953-8. DOI: $10.1111 /$ jgh. 13249.

149.Gonzalez C.A., Sanz-Anquela J.M., Gisbert J.P., Correa $P$. Utility of subtyping intestinal metaplasia as marker of gastric cancer risk. A review of the evidence. Int J Cancer. 2013;133(5):1023-32. DOI: 10.1002/ijc.28003

150. Conchillo J.M., Houben G., de Bruine A., Stockbrügger $R$. Is type III intestinal metaplasia an obligatory precancerous lesion in intestinal-type gastric carcinoma? Eur J Cancer Prev. 2001; 10(4):307 -312. doi: 10.1097/00008469-200108000-00003.

151.Rokkas T., Sechopoulos P., Pistiolas D., Georgios Margantinis, Koukoulis G. Helicobacter pylori infection and gastric histology in first-degree relatives of gastric cancer patients: a meta-analysis. Eur J Gastroenterol Hepatol. 2010; 22(9):1128-33. DOI: 10.1097/MEG.0b013e3283398d37

152. Marcos-Pinto R., Dinis-Ribeiro M., Carneiro F., Wen X., Lopes C., Figueiredo C., et al. First-degree relatives of early-onset gastric cancer patients show a high risk for gas tric cancer: phenotype and genotype profile. Virchows Arch. 2013;463(3):391-9. DOI: 10.1007/s00428013-1458-5

153. Vannella L., Lahner E., Osborn J., Annibale B. Systematic review: gastric cancer incidence in pernicious anaemia. Aliment Pharmacol Ther. 2013;37(4):375-82. DOI: $10.1111 /$ apt. 12177

154.Sjoblom S.M., Sipponen P., Jarvinen H. Gastroscopic follow up of pernicious anaemia patients. Gut. 1993;34(1):28-32. DOI: 10.1136/gut.34.1.28

155.Brinton L.A., Gridley G., Hrubec Z., Hoover R., Fraumeni J.F. Cancer risk following pernicious anaemia. $\mathrm{Br} \mathrm{J}$ Cancer. 1989;59(5):810 -3. DOI: 10.1038/bjc.1989.169

156. Kim H.H., Uedo N. What Have We Accomplished in Endoscopic Image Analysis for Atrophic Gastritis? Korean J Helicobacter Upper Gastrointest Research. 2013;13(1):619. DOI: $10.7704 /$ kjhugr.2013.13.1.6

157.Toyoshima O., Nishizawa T., Koike K. Endoscopic Kyoto classification of Helicobacter pylori infection and gastric cancer risk diagnosis. World J Gastroenterol 2020;26(5):466-77. DOI: 10.3748/wjg.v26.i5.466 


\section{Приложение А2. Методология разработки клинических рекомендаций}

Предлагаемые рекомендации имеют своей целью довести до практических врачей современные представления об этиологии и патогенезе гастрита и дуоденита, познакомить с применяющимся в настоящее время алгоритмом диагностики и лечения.

\section{Џелевая аудитория данных клинических рекомендаций:}

1. Врачи-гастроэнтерологи.

2. Врачи общей практики (семейные врачи).

3. Врачи-терапевты.

4. Врачи-эндоскописты.

5. Врачи-онкологи.

Таблица 1. Шкала оценки уровней достоверности доказательств (УдД) для методов диагностики (диагностических вмешательств)

Table 1. Strength of evidence scale in diagnostic methods (diagnostic interventions)

\begin{tabular}{|c|l|}
\hline Удд & \multicolumn{1}{|c|}{ Расшифровка } \\
\hline 1 & $\begin{array}{l}\text { Систематические обзоры исследований с контролем референсным методом или систематический } \\
\text { обзор рандомизированных клинических исследований с применением метаанализа }\end{array}$ \\
\hline 2 & $\begin{array}{l}\text { Отдельные исследования с контролем референсным методом или отдельные рандомизированные } \\
\text { клинические исследования и систематические обзоры исследований любого дизайна, за } \\
\text { исключением рандомизированных клинических исследований, с применением метаанализа }\end{array}$ \\
\hline 3 & $\begin{array}{l}\text { Ссследования без последовательного контроля референсным методом или исследования } \\
\text { неференсным методом, не являющимся независимым от исследуемого метода, или }\end{array}$ \\
\hline 4 & Несравдомизированные сравнительные исследования, в том числе когортные исследования \\
\hline 5 & Имеется лишь обоснование механизма действия или мнение экспертов \\
\hline
\end{tabular}

Таблица 2. Уровни достоверности доказательств с указанием использованной классификации уровней достоверности доказательств (УДД)

Table 2. Strength of evidence levels by their classification criteria

\begin{tabular}{|c|c|}
\hline УдД & Расшифровка \\
\hline 1 & Систематический обзор рандомизированных клинических исследований с применением метаанализа \\
\hline 2 & $\begin{array}{l}\text { Отдельные рандомизированные клинические исследования и систематические обзоры исследований } \\
\text { любого дизайна, за исключением рандомизированных клинических исследований, с применением } \\
\text { метаанализа }\end{array}$ \\
\hline 3 & Нерандомизированные сравнительные исследования, в том числе когортные исследования \\
\hline 4 & $\begin{array}{l}\text { Несравнительные исследования, описание клинического случая или серии случаев, исследование } \\
\text { «случай-контроль» }\end{array}$ \\
\hline 5 & $\begin{array}{l}\text { Имеется лишь обоснование механизма действия вмешательства (доклинические исследования) или } \\
\text { мнение эксперта }\end{array}$ \\
\hline
\end{tabular}


Таблища 3. Уровни убедительности рекомендаций (УУР) с указанием использованной классификации уровней убедительности рекомендаций

Table 3. Credibility of recommendation levels by their classification criteria

\begin{tabular}{|c|l|}
\hline Уур & \multicolumn{1}{|c|}{ Расшифровка } \\
\hline А & $\begin{array}{l}\text { Сильная рекомендация (все рассматриваемые критерии эффективности (исходы) являются } \\
\text { важными, все исследования имеют высокое или удовлетворительное методологическое качество, их } \\
\text { выводы по интересующим исходам являются согласованными) }\end{array}$ \\
\hline В & $\begin{array}{l}\text { Условная рекомендация (не все рассматриваемые критерии эффективности (исходы) являются } \\
\text { важными, не все исследования имеют высокое или удовлетворительное методологическое качество } \\
\text { и/или их выводы по интересующим исходам не являются согласованными) }\end{array}$ \\
\hline С & $\begin{array}{l}\text { Слабая рекомендация (отсутствие доказательств надлежащего качества (все рассматриваемые } \\
\text { критерии эффективности (исходы) являются неважными, все исследования имеют низкое } \\
\text { методологическое качество и их выводы по интересующим исходам не являются согласованными) }\end{array}$ \\
\hline
\end{tabular}

\section{Порядок обновления клинических рекомендаций}

Механизм обновления клинических рекомендаций предусматривает их систематическую актуализацию - не реже чем один раз в три года, а также при появлении новых данных с позиции доказательной медицины по вопросам диагностики, лечения, профилактики и реабилитации конкретных заболеваний, наличии обоснованных дополнений/замечаний к ранее утвержденным КР, но не чаще 1 раза в 6 месяцев.

\section{Приложение АЗ. Справочные материалы, включая соответствие показаний к применению и противопоказаний, способов применения и доз лекарственных препаратов, инструкции по применению лекарственного препарата}

Данные клинические рекомендации разработаны с учетом следующих нормативно-правовых документов:

1. Приказ Министерства здравоохранения и социального развития Российской Федерации от 02.06.2010 № 415н «Об утверждении Порядка оказания медицинской помощи населению при заболеваниях гастроэнтерологического профиля».

2. Приказ Министерства здравоохранения Российской Федерации от 10 мая 2017 г. № 203н «Об утверждении критериев оценки качества медицинской помощи».

3. Приказ Министерства здравоохранения Российской Федерации от 22.11 .2004 г. № 248 «Об утверждении стандарта медицинской помощи больным хроническим гастритом, дуоденитом, диспепсией».

4. Приказ Министерства здравоохранения РФ от 29 марта 2019 г. № 173н «Об утверждении порядка проведения диспансерного наблюдения за взрослыми». 


\section{Приложение Б. Алгоритмы действий врача \\ Annex B. Medical algorithms}

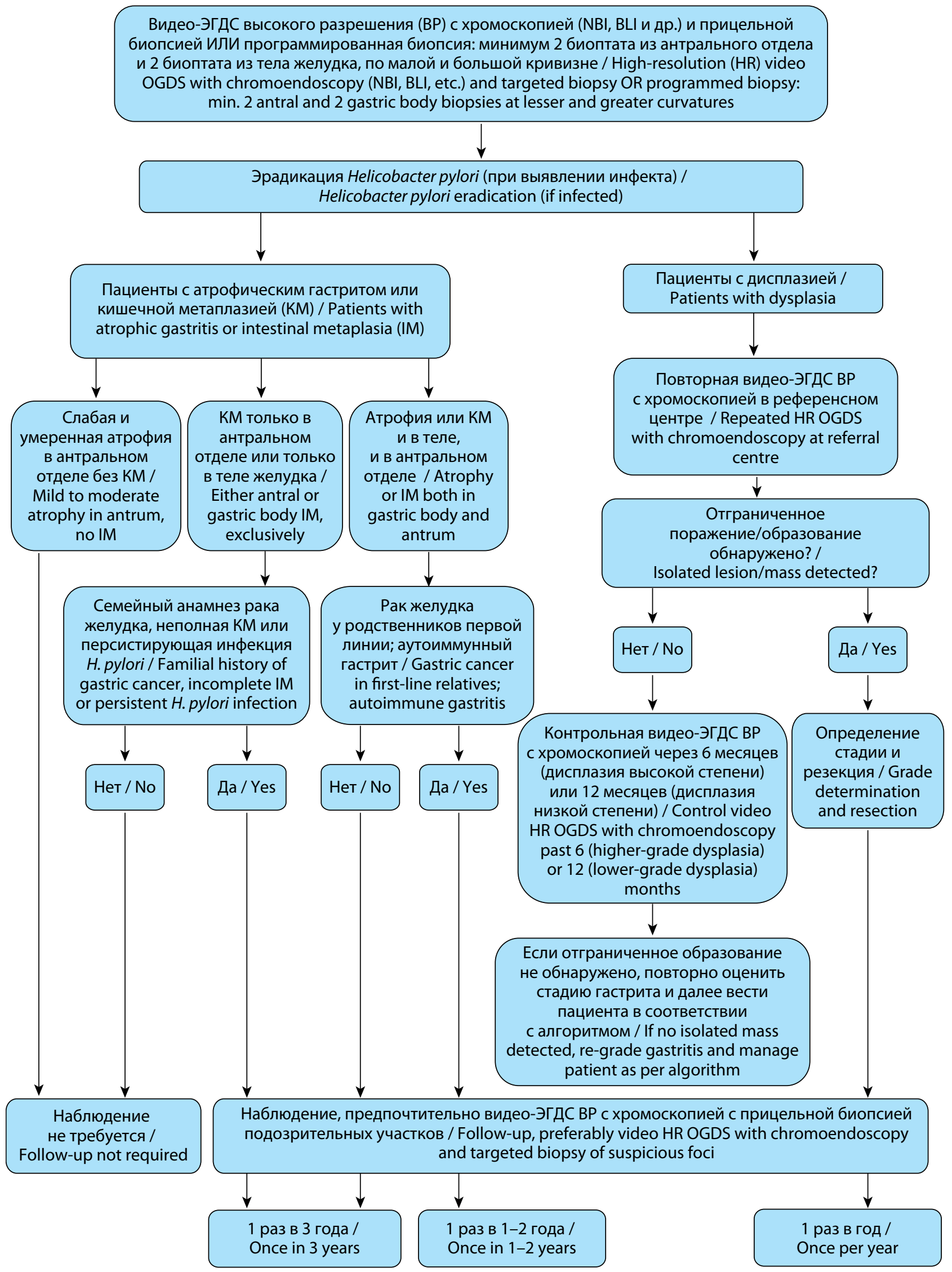




\section{Приложение В. Информация для пациента}

Основным фактором, вызывающим гастрит, в настоящее время признан микроорганизм, называемый пилорическим геликобактером. Поэтому каждый пациент, у которого выявлен гастрит, должен быть обследован на наличие данной инфекции. При ее подтверждении необходимо проведение лечения, направленного на уничтожение данных бактерий (эрадикация), с последующим контролем через 4-6 недель. При неэффективности проведенного лечения следует провести повторный курс терапии с другой схемой назначения лекарственных средств. Важно соблюдать приверженность к лечению и строго контролировать прием лекарственных препаратов. Эрадикационная терапия, приводящая к уничтожению пилорического геликобактера, сейчас считается основной мерой, направленной на оздоровление слизистой оболочки желудка, и профилактику рака желудка. Наличие рака желудка у близких родственников (родители, бабушки и дедушки) служит дополнительным основанием для проведения лечения против пилорического геликобактера.

\section{Приложение Г. Шкалы оценки, вопросники и другие оценочные инструменты состояния пациента, приведенные в клинических рекомендациях}

Классификация атрофического гастрита по Кимура - Такемото [27, 28]. Рисунок воспроизведен из [156] в соответствии с Creative Commons Attribution Non-Commercial License (http://creativecommons.org/licenses/by-nc/3.0).

Kimura-Takemoto classification of atrophic gastritis [27, 28]. Reproduced from [156] under Creative Commons Attribution Non-Commercial License (http://creativecommons.org/licenses/by-nc/3.0).

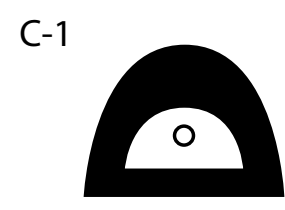

$\mathrm{C}-2$

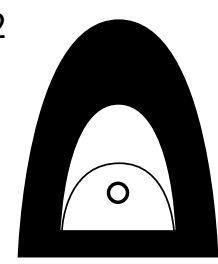

C-3

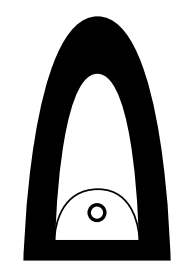

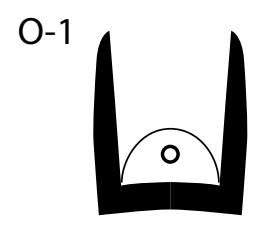

$0-2$

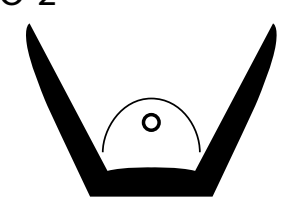

O-3

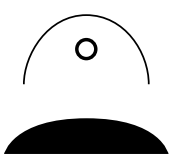

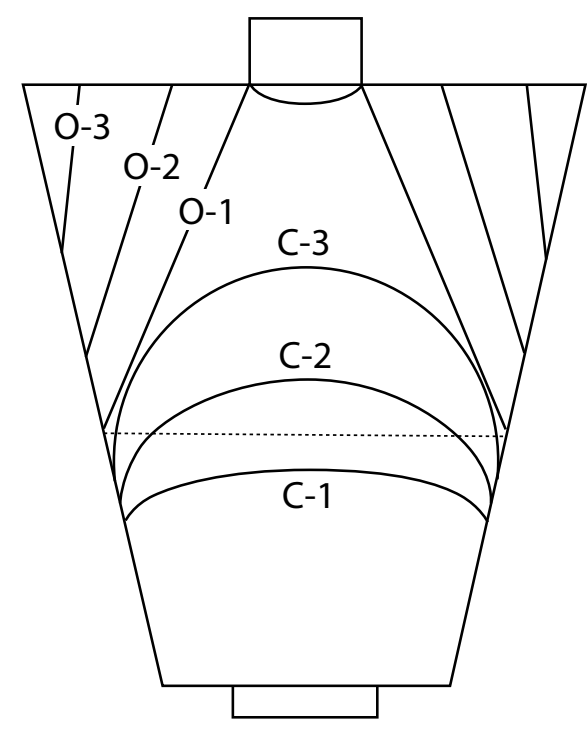

Гастрит закрытого типа (closed type: C-1, C-2, C-3): граница атрофии распространяется по малой кривизне тела желудка.

Гастрит открытого типа (open type: O-1, O-2, O-3, Op): граница атрофии распространяется по передней и задней стенкам желудка.

C-1 - атрофия ограничена антральным отделом.

C-2 - атрофия распространяется выше угла желудка, но ограничена небольшой областью малой кривизны тела желудка.

C-3 - атрофия занимает бо́льшую часть малой кривизны тела желудка, но не достигает кардии.

О-1 - атрофия распространяется на тело желудка выше кардии; граница атрофии располагается между малой кривизной и передней стенкой.

О-2 - граница атрофии проходит по передней стенке тела желудка.

O-3 - атрофия занимает почти весь желудок; граница проходит между передней стенкой и большой кривизной.

Ор - атрофический пангастрит. 
Эндоскопическая картина, соответствующая классификации атрофического гастрита по Кимура - Такемото [27, 28]. Граница атрофии обозначена прерывистой линией. А - C1; В - C2; $\mathrm{C}-\mathrm{C} 3 ; \mathrm{D}-\mathrm{O} 1 ; \mathrm{E}-\mathrm{O} 2 ; \mathrm{F}$ - O3. Рисунок воспроизведен из [157] в соответствии с Creative Commons Attribution Non Commercial (CC BY-NC 4.0) license.

Endoscopy consistent with Kimura-Takemoto classification of atrophic gastritis [27, 28]. Atrophy demarked by dashed line. A: C1; B: C2; C: C3; D: O1; E: O2; F: O3. Reproduced from [157] under Creative Commons Attribution Non-Commercial License (CC BY-NC 4.0).
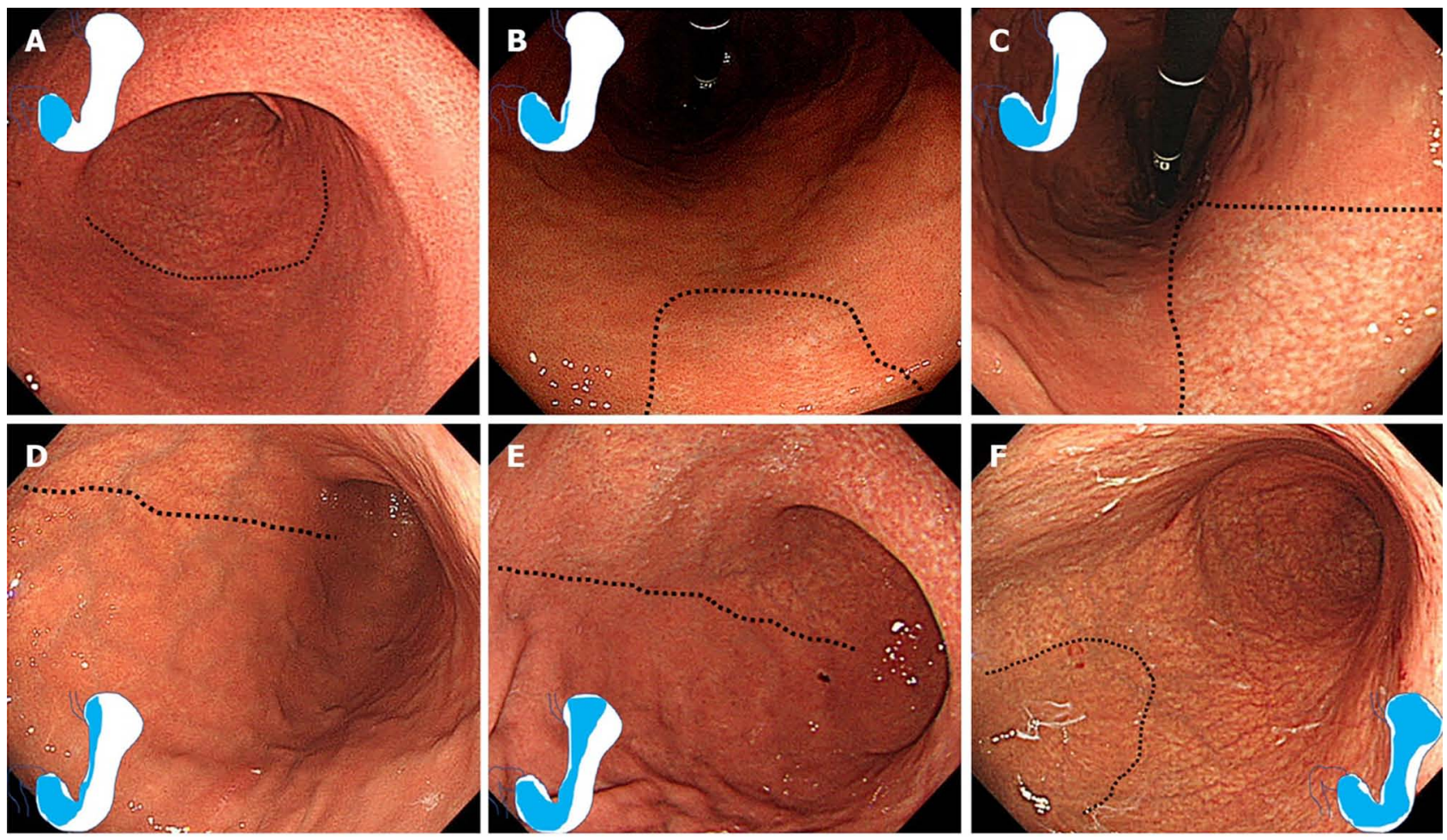

\section{Сведения об авторах}

Ивашкин Владимир Трофимович - доктор медицинских наук, академик РАН, профессор, заведующий кафедрой пропедевтики внутренних болезней, гастроэнтерологии и гепатологии ФГАОУ ВО «Первый Московский государственный медицинский университет им. И.М. Сеченова» (Сеченовский университет) Министерства здравоохранения Российской Федерации.

Контактная информация: ivashkin_v_t@staff.sechenov.ru; 119435, г. Москва, ул. Погодинская, д. 1, стр. 1.

ORCID: https://orcid.org/0000-0002-6815-6015

Маев Игорь Вениаминович - доктор медицинских наук, академик РАН, профессор, заведующий кафедрой пропедевтики внутренних болезней и гастроэнтерологии ФГБОУ ВО «Московский государственный медико-стоматологический университет им. А.И. Евдокимова» Министерства здравоохранения Российской Федерации.

Контактная информация: igormaev@rambler.ru;

127473, г. Москва, ул. Делегатская, д. 20, стр. 1

ORCID: https://orcid.org/0000-0001-6114-564X

Лапина Татьяна Львовна* - кандидат медицинских наук, доцент кафедры пропедевтики внутренних болезней лечебного факультета ФГАОУ ВО «Первый Московский государственный медицинский университет им. И.М. Сеченова» (Сеченовский университет) Министерства здравоохранения Российской Федерации.

Контактная информация: lapina_t_1@staff.sechenov.ru;

119435, г. Москва, ул. Погодинская, д. 1, стр. 1.

ORCID: https://orcid.org/0000-0003-4456-8725

\section{Information about the authors}

Vladimir T. Ivashkin - Dr. Sci. (Med.), Full Member of the Russian Academy of Sciences, Prof., Departmental Head, Department of Internal Disease Propaedeutics, I.M. Sechenov First Moscow State Medical University.

Contact information: ivashkin_v_t@staff.sechenov.ru; 119435, Moscow, Pogodinskaya str., $\overline{1}, \bar{b}$ ld. 1.

ORCID: https://orcid.org/0000-0002-6815-6015

Igor V. Maev - Dr. Sci. (Med.), Full Member of the Russian Academy of Sciences, Prof., Head of the Chair of Internal Disease Propaedeutics and Gastroenterology, Yevdokimov Moscow State University of Medicine and Dentistry.

Contact information: igormaev@rambler.ru; 127473, Moscow, Delegatskaya str., 20, bld. 1.

ORCID: https://orcid.org/0000-0001-6114-564X

Tatyana L. Lapina* - Dr. Sci. (Med.), Prof., Department of Internal Disease Propaedeutics, I.M. Sechenov First Moscow State Medical University.

Contact information: tatlapina@gmail.com;

119991, Moscow, Pogodinskaya str., 1, bld. 1.

ORCID: https://orcid.org/0000-0003-4456-8725 
Федоров Евгений Дмитриевич - доктор медицинских наук, профессор, главный научный сотрудник кафедры госпитальной хирургии № 2 с научно-исследовательской лабораторией хирургической гастроэнтерологии и эндоскопии ФГАОУ ВО «Российский национальный исследовательский медицинский университет им. Н.И. Пирогова» Министерства здравоохранения Российской Федерации.

Контактная информация: efedo@mail.ru;

119415, г. Москва, ул. Лобачевского, д. 42.

ORCID: https://orcid.org/0000-0002-6036-7061

Шептулин Аркадий Александрович - доктор медицинских наук, профессор кафедры пропедевтики внутренних болезней, гастроэнтерологии и гепатологии ФГАОУ ВО «Первый Московский государственный медицинский университет им. И.М. Сеченова» (Сеченовский университет) Министерства здравоохранения Российской Федерации.

Контактная информация: 119435, г. Москва, ул. Погодинская, д. 1, стр. 1.

ORCID: https://orcid.org/0000-0002-1395-9566

Трухманов Александр Сергеевич - доктор медицинских наук, профессор кафедры пропедевтики внутренних болезней, гастроэнтерологии и гепатологии ФГАОУ ВО «Первый Московский государственный медицинский университет им. И.М. Сеченова» (Сеченовский университет) Министерства здравоохранения Российской Федерации.

Контактная информация: alexander.trukhmanov@gmail.com; 119991, г. Москва, ул. Погодинская, д. 1, стр. 1.

ORCID: https://orcid.org/0000-0003-3362-2968

Кононов Алексей Владимирович - доктор медицинских наук, профессор, заведующий кафедрой патологической анатомии ФГБОУ ВО «Омский государственный медицинский университет» Министерства здравоохранения Российской Федерации.

Контактная информация: ogmapath@mail.ru;

644099, г. Омск, ул. Ленина, д. 12.

ORCID: https://orcid.org/0000-0001-8607-7831

Абдулхаков Рустам Аббасович - доктор медицинских наук, профессор ФГБОУ ВО «Казанский государственный медицинский университет» Министерства здравоохранения Российской Федерации.

Контактная информация: rustemabdul@mail.ru;

420012, Республика Татарстан, г. Казань, ул. Бутлерова, д. 49. ORCID: https://orcid.org/0000-0002-1509-6776

Алексеева Ольга Поликарповна - доктор медицинских наук, профессор кафедры госпитальной терапии и общеврачебной практики им. В.Г. Вогралика ФГБОУ ВО «Приволжский исследовательский медицинский университет» Министерства здравоохранения Российской Федерации. Контактная информация: al_op@mail.ru;

603005 , г. Нижний Новгород, пл. Минина и Пожарского, д. $10 / 1$

ORCID: https://orcid.org/0000-0002-1475-6584

Алексеенко Сергей Алексеевич - доктор медицинских наук, профессор, заведующий кафедрой госпитальной терапии ФГБОУ ВО «Дальневосточный государственный медицинский университет» Министерства здравоохранения Российской Федерации; руководитель Клиники внутренних болезней Дорожной клинической больницы на ст. Хабаровск-1 Дальневосточной железной дороги (ДВЖД).

Контактная информация: sa.alexeenko@gmail.com;

680000, г. Хабаровск, ул. Муравьева-Амурского, д. 35.
Evgeny D. Fedorov - Dr. Sci. (Med.), Prof., Chief Researcher, Department of Hospital Surgery No. 2 with the Research Laboratory of Surgical Gastroenterology and Endoscopy, Pirogov Russia National Research Medical University.

Contact information: efedo@mail.ru;

119415, Moscow, Lobachevskogo str., 42.

ORCID: https://orcid.org/0000-0002-6036-7061

Arkadiy A. Sheptulin - Dr. Sci. (Med.), Prof., Department of Internal Disease Propaedeutics, I.M. Sechenov First Moscow State Medical University.

Contact information: 119991, Moscow, Pogodinskaya str., 1, bld. 1.

ORCID: https://orcid.org/0000-0002-1395-9566

Aleksandr S. Trukhmanov - Dr. Sci. (Med.), Prof., Department of Internal Disease Propaedeutics, I.M. Sechenov First Moscow State Medical University.

Contact information: alexander.trukhmanov@gmail.com; 119991, Moscow, Pogodinskaya str., 1, bld. 1.

ORCID: https://orcid.org/0000-0003-3362-2968

Alexey V. Kononov - Dr. Sci. (Med.), Prof., Head of the Pathology Department, Omsk State Medical University.

Contact information: ogmapath@mail.ru;

644099, Omsk, Lenina str., 12.

Rustam A. Abdulkhakov - Dr. Sci. (Med.), Prof., Kazan State Medical University, Kazan, Russian Federation.

Contact information: rustemabdul@mail.ru;

420012, Tatarstan, Kazan, Butlerova str., 49.

ORCID: https://orcid.org/0000-0002-1509-6776

Olga P. Alekseeva - Dr. Sci. (Med.), Prof., Chair of Hospital Therapy and General Practice named after V.G. Vogralik, Privolzhsky Research Medical University.

Contact information: al_op@mail.ru;

603005, Nizhny Novgorod, Minina i Pozharskogo sq., 10/1.

ORCID: https://orcid.org/0000-0002-1475-6584

Sergey A. Alekseenko - Dr. Sci. (Med.), Prof., Head of the Chair of Hospital Therapy, Far-Eastern State Medical University; Head of the Clinic of Internal Medicine, Khabarovsk-1 Railway Clinical Hospital, Far-Eastern Railways.

Contact information: sa.alexeenko@gmail.com;

680000, Khabarovsk, Muravyova-Amurskogo str., 35. 
Андреев Дмитрий Николаевич - кандидат медицинских наук, ассистент кафедры пропедевтики внутренних болезней и гастроэнтерологии ФГБОУ ВО «Московский государственный медико-стоматологический университет им. А.И. Евдокимова» Министерства здравоохранения Российской Федерации; научный сотрудник лаборатории функциональных методов исследования в гастроэнтерологии.

Контактная информация: dna-mit8@mail.ru;

127473, г. Москва, ул. Делегатская, д. 20, стр. 1.

ORCID: https://orcid.org/0000-0002-4007-7112

Баранская Елена Константиновна - доктор медицинских наук, профессор кафедры пропедевтики внутренних болезней, гастроэнтерологии и гепатологии ФГАОУ ВО «Первый Московский государственный медицинский университет им. И.М. Сеченова» (Сеченовский университет) Министерства здравоохранения Российской Федерации

Контактная информация: ebaranskaya@yandex.ru;

119991, г. Москва, ул. Погодинская, д. 1, стр. 1.

Дехнич Наталья Николаевна - доктор медицинских наук, доцент кафедры факультетской терапии; проректор по дополнительному профессиональному образованию и развитию регионального здравоохранения ФГБОУ ВО «Смоленский государственный медицинский университет» Министерства здравоохранения Российской Федерации.

Контактная информация: n.dekhnich@mail.ru;

214019, г. Смоленск, ул. Крупской, д. 28.

ORCID: https://orcid.org/0000-0002-6144-3919

Кляритская Ирина Львовна - доктор медицинских наук, профессор, заведующая кафедрой терапии, гастроэнтерологии, кардиологии и ОВП (семейной медицины) Медицинской академии им. С.И. Георгиевского ФГАОУ ВО «Крымский федеральный университет им. В.И. Вернадского».

Контактная информация: klira3@yandex.ru;

295017, Республика Крым, г. Симферополь, бульвар Ленина, д. $5 / 7$.

ORCID: https://orcid.org/0000-0001-9840-7885

Козлов Роман Сергеевич - доктор медицинских наук, профессор, президент Межрегиональной ассоциации по клинической микробиологии и антимикробной химиотерапии, ФГБОУ ВО «Смоленский государственный медицинский университет» Министерства здравоохранения Российской Федерации.

Контактная информация: Roman.Kozlov@antibiotic.ru;

214019, г. Смоленск, ул. Крупской, д. 28.

Коган Евгения Алтаровна - доктор медицинских наук, профессор, заведующая кафедрой патологической анатомии ФГАОУ ВО «Первый Московский государственный университет им. И.М. Сеченова» (Сеченовский университет) Министерства здравоохранения Российской Федерации.

Контактная информация: koganevg@gmail.com;

119991, г. Москва, ул. Трубецкая, д. 8, стр. 2.

Королев Михаил Павлович - доктор медицинских наук, заведующий кафедрой общей хирургии с курсом эндоскопии ФГБОУ ВО «Санкт-Петербургский государственный педиатрический медицинский университет» Министерства здравоохранения Российской Федерации.

Контактная информация: korolevmp@yandex.ru;

119014, г. Санкт-Петербург, Литейный проспект, д. 56.
Dmitriy N. Andreev - Cand. Sci. (Med.), Research Assistant, Chair of Internal Medicine Propaedeutics and Gastroenterology, Yevdokimov Moscow State University of Medicine and Dentistry.

Contact information: dna-mit8@mail.ru;

127473, Moscow, Delegatskaya str., 20, bld. 1.

ORCID: https://orcid.org/0000-0002-4007-7112

Elena K. Baranskaya - Dr. Sci. (Med.), Prof., Chair of Internal Medicine Propaedeutics, Gastroenterology and Hepatology, Sechenov First Moscow State Medical University (Sechenov University).

Contact information: ebaranskaya@yandex.ru; 119991, Moscow, Pogodinskaya str., 1, bld. 1.

Natalya N. Dekhnich - Dr. Sci. (Med.), Assoc. Prof., Department of Faculty Therapy; Smolensk State Medical University.

Contact information: n.dekhnich@mail.ru;

214019, Smolensk, Krupskaya str., 28.

ORCID: https://orcid.org/0000-0002-6144-3919

Irina L. Klyaritskaya - Dr. Sci. (Med.), Prof., Head of the Department of Therapy, Gastroenterology, Cardiology and General Practice (Family Medicine), Medical Academy named after S.I. Georgievsky, Vernadsky Crimean Federal University. Contact information: klira3@yandex.ru;

295017, Republic of Crimea, Simferopol, Lenina blvd, 5/7.

ORCID: https://orcid.org/0000-0001-9840-7885

Roman S. Kozlov - Dr. Sci. (Med.), Prof., President, Transregional Association for Clinical Microbiology and Antimicrobial Chemotherapy, Smolensk State Medical University.

Contact information: 214019, Smolensk, Krupskoy str., 28.

Evgenya A. Kogan - Dr. Sci. (Med.), Prof., Departmental Head, Department of Pathological Anatomy, I.M. Sechenov First Moscow State Medical University (Sechenov University). Contact information: koganevg@gmail.com; 119991, Moscow, Trubetskaya str., 8, bld. 2.

Mikhail P. Korolev - Dr. Sci. (Med.), Departmental Head, Department of General Surgery with an Endoscopy Course, St. Petersburg State Paediatric Medical University.

Contact information: korolevmp@yandex.ru;

119014, St. Petersburg, Liteiny ave., 56. 
Корочанская Наталья Всеволодовна - доктор медицинских наук ФГБОУ ВО «Кубанский государственный медицинский университет» Министерства здравоохранения Российской Федерации; ГБУЗ «Краевая клиническая больница № 2» Министерства здравоохранения Краснодарского края.

Контактная информация: nvk-gastro@mail.ru;

350012, г. Краснодар, ул. Красных Партизан, д. 6, корп. 2. ORCID: https://orcid.org/0000-0002-5538-9418

Курилович Светлана Арсентьевна - доктор медицинских наук, профессор, заведующая лабораторией гастроэнтерологии Научно-исследовательского института терапии и профилактической медицины ФГБОУ ВО «Новосибирская государственная медицинская академия» Министерства здравоохранения Российской Федерации.

Контактная информация: kurilovich@yandex.ru;

630091, г. Новосибирск, Красный проспект, д. 52.

Ливзан Мария Анатольевна - доктор медицинских наук, профессор, ректор; заведующая кафедрой факультетской терапии профессиональных болезней ФГБОУ ВО «Омский государственный медицинский университет» Министерства здравоохранения Российской Федерации.

Контактная информация: e-mail: mlivzan@yandex.ru;

644099, г. Омск, ул. Ленина, д. 12.

ORCID: https://orcid.org/0000-0002-6581-7017

SCOPUS Author ID: 24341682600

Осипенко Марина Федоровна - доктор медицинских наук, профессор, заведующая кафедрой пропедевтики внутренних болезней ФГБОУ ВО «Новосибирский государственный медицинский университет» Министерства здравоохранения Российской Федерации.

Контактная информация: ngma@bk.ru;

630091, Новосибирск, Красный проспект, д. 52.

Павлов Павел Владимирович - кандидат медицинских наук, заведующий отделением диагностической и лечебной эндоскопии Университетской клинической больницы № 2 ФГАОУ ВО «Первый Московский государственный медицинский университет им. И.М. Сеченова» (Сеченовский университет) Министерства здравоохранения Российской Федерации.

Контактная информация: pvpavlov@yandex.ru;

119435, г. Москва, ул. Погодинская, д. 1, стр. 1.

Пирогов Сергей Сергеевич - доктор медицинских наук, заведующий отделом эндоскопии Национального медицинского исследовательского центра радиологии им. П.А. Герцена - филиала ФГБУ «Московский научно-исследовательский онкологический институт» Министерства здравоохранения Российской Федерации.

Контактная информация: pirogov@mail.ru;

125284, г. Москва, 2-й Боткинский пр., д. 3

ORCID: https://orcid.org/0000-002-8101-2155

Сарсенбаева Айман Силкановна - доктор медицинских наук, профессор кафедры терапии, декан Института дополнительного профессионального образования ЮжноУральского государственного медицинского университета Министерства здравоохранения Российской Федерации.

Контактная информация: aiman-ss@yandex.ru;

454092, г. Челябинск, ул. Воровского, д. 64

ORCID: https://orcid.org/0000-0001-5922-2271
Natalya V. Korochanskaya - Dr. Sci. (Med.), Kuban StateMedical University, Regional Clinical Hospital No. 2. Contact information: nvk-gastro@mail.ru;

350012, Krasnodar, Krasnykh Partizan str., 6, bld. 2.

ORCID: https://orcid.org/0000-0002-5538-9418

Svetlana A. Kurilovich - Dr. Sci. (Med.), Prof., Head of the Laboratory of Gastroenterology, Research Institute of Therapy and Preventive Medicine, Novosibirsk State Medical Academy. Contact information: kurilovich@yandex.ru;

630091, Novosibirsk, Krasnyi ave., 52

Maria A. Livzan - Dr. Sci. (Med.), Prof., Rector; Head of the Chair of Faculty Therapy and Professional Diseases, Omsk State Medical University.

Contact information: mlivzan@yandex.ru;

644099, Omsk, Lenina str., 12.

ORCID: https://orcid.org/0000-0002-6581-7017

SCOPUS Author ID: 24341682600

Marina F. Osipenko - Dr. Sci. (Med.), Prof., Head of the Chair of Internal Diseases Propedeutics, Novosibirsk State Medical University.

Contact information: ngma@bk.ru;

630091, Novosibirsk, Krasnyi ave., 52.

Pavel V. Pavlov - Cand. Sci. (Med.), Departmental Head, Department of Diagnostic and Therapeutic Endoscopy, University Clinical Hospital No. 2, I.M. Sechenov First Moscow State Medical University.

Contact information: pvpavlov@yandex.ru;

119435, Moscow, Pogodinskaya str., 1, bld. 1.

Sergey S. Pirogov - Dr. Sci. (Med.), Departmental Head, Endoscopy Department, P.A. Gertsen National Medical Research Centre for Radiology, branch of the Moscow Research Institute of Oncology.

Contact information: pirogov@mail.ru;

125284, Moscow, 2nd Botkinsky travel, 3.

ORCID: https://orcid.org/0000-002-8101-2155

Aiman S. Sarsenbaeva - Dr. Sci. (Med.), Prof. of the Department of Therapy, Dean of Institute of Additional Professional Education, South Ural State Medical University. Contact information: aiman-ss@yandex.ru;

tel.: +7 (902) 899-67-58

454092, Chelyabinsk, Vorovskogo str., 64. ORCID: https:// orcid.org/0000-0001-5922-2271 
Симаненков Владимир Ильич - доктор медицинских наук, профессор кафедры внутренних болезней, клинической фармакологии и нефрологии ФБГОУ ВО «СевероЗападный государственный медицинский университет им. И.И. Мечникова» Министерства здравоохранения Российской Федерации.

Контактная информация: visimanenkov@mail.ru;

191015, г. Санкт-Петербург, ул. Кирочная, д. 41

ORCID: https://orcid.org/ 0000-0002-1956-0070

Тертычный Александр Семенович - доктор медицинских наук, профессор кафедры патологической анатомии имени академика А.И. Струкова ФГАОУ ВО «Первый Московский государственный медицинский университет им. И.М. Сеченова» (Сеченовский университет) Министерства здравоохранения Российской Федерации.

Контактная информация: atertychnyy@yandex.ru;

119048, г. Москва, ул. Трубецкая, д. 8, стр. 2.

ORCID: https://orcid.org/0000-0001-5635-6100

Ткачев Александр Васильевич - доктор медицинских наук, профессор, заведующий кафедрой пропедевтики внутренних болезней ФГБОУ ВО «Ростовский государственный медицинский университет» Министерства здравоохранения Российской Федерации.

Контактная информация: tkachev@aaanet.ru;

344022, г. Ростов-на-Дону, Нахичеванский пер., д. 29.

Успенский Юрий Павлович - профессор, доктор медицинских наук, заведующий кафедрой факультетской терапии им. профессора В.А. Вальдмана ФГБОУ ВО «Санкт-Петербургский государственный педиатрический медицинский университет» Министерства здравоохранения Российской Федерации.

Контактная информация: uspenskiy65@mail.ru;

194100, Санкт-Петербург, ул. Литовская, д. 2.

ORCID: https://orcid.org/0000-0001-6434-1267

Хлынов Игорь Борисович - доктор медицинских наук, доцент кафедры факультетской терапии и гериатрии ФГБОУ $\mathrm{BO}$ «Уральский государственный медицинский университет» Министерства здравоохранения Российской Федерации.

Контактная информация: hlinov.doc@yandex.ru;

620028, г. Екатеринбург, ул. Репина, д. 3.

ORCID: https://orcid org/ 0000-0002-0944-9811

Цуканов Владислав Владимирович - профессор, доктор медицинских наук, заведующий Клиническим отделением патологии пищеварительной системы у взрослых и детей ФБГНУ «Федеральный исследовательский центр "Красноярский научный центр Сибирского отделения Российской академии наук”, обособленное подразделение НИИ медицинских проблем Севера.

Контактная информация: gastro@impn.ru;

660022, г. Красноярск, ул. Партизана Железняка, д. Зг.

ORCID: https://orcid.org/0000-0002-9980-2294
Vladimir I. Simanenkov - Dr. Sci. (Med.), Prof., Chair of Internal Diseases, Clinical Pharmacology and Nephrology, I.I. Mechnikov North-West State Medical University.

Contact information: visimanenkov@mail.ru;

191015, St.-Petersburg, Kirochnaya str., 41.

ORCID: https://orcid.org/0000-0002-1956-0070

Alexander S. Tertychny - Dr. Sci. (Med.), Prof., Department of Pathological Anatomy named after academician A.I. Strukov, Sechenov First Moscow State Medical University (Sechenov University).

Contact information: atertychnyy@yandex.ru;

119048, Moscow, Trubetskaya str., 8, bld. 2.

ORCID: https://orcid.org/0000-0001-5635-6100

Aleksandr V. Tkachev - Doc. Sci. (Med.), Prof., Departmental Head, Department of Internal Diseases Propaedeutics, Rostov State Medical University.

Contact information: tkachev@aaanet.ru;

344022, Rostov-on-Don, Nakhichevansky per., 29.

Yury P. Uspensky - Dr. Sci. (Med.), Prof., Head of the Chair of Faculty Therapy named after Prof. V.A. Valdman, Saint-Petersburg State Pediatric Medical University.

Contact information: uspenskiy65@mail.ru;

194100, St. Petersburg, Litovskaya str., 2.

ORCID: https://orcid.org/0000-0001-6434-1267

Igor B. Khlynov - Dr. Sci. (Med.), Assoc. Prof., Chair of Intermediate Therapy and Geriatrics, Ural State Medical University.

Contact information: hlinov.doc@yandex.ru;

620028, Ekaterinburg, Repina str., 3.

ORCID: https://orcid.org/0000-0002-0944-9811

Vladislav V. Tsukanov - Dr. Sci. (Med.), Prof., Head of the Clinical Department of Adult and Infant Digestive Pathology, Research Institute for Medical Problems in the North Division of Krasnoyarsk Scientific Centre of the Siberian Branch of the RAS.

Contact information: gastro@impn.ru;

660022, Krasnoyarsk, Partizana Zheleznyaka str., 3г.

ORCID: https://orcid.org/0000-0002-9980-2294.

Поступила: 02.09.2021 Принята: 07.09.2021 Опубликована: 30.09.2021 Submitted: 02.09.2021 Accepted: 07.09.2021 Published: 30.09.2021

* Автор, ответственный за переписку / Corresponding author 